\title{
Research Paper \\ The efficacy of acceptance and commitment based therapy on marital satisfaction and self- efficiency of mothers with children with cerebral palsy
}

\begin{abstract}
Citation: Zarei F, Asadpour E, Mohsenzadeh F. The efficacy of acceptance and commitment based therapy on marital satisfaction and self-efficiency of mothers with children with cerebral palsy. J of Psychological Science. 2021; 20(105): 1493-1511.
\end{abstract}

Farshad Zarei ${ }^{1}$, Esmail Asadpour ${ }^{2}$, Farshad Mohsenzadeh ${ }^{2}$

1. Ph.D Student, Department of Consultation and Guidance, Kharazmi University, Tehran, Iran.

2. Assistant Professor, Department of Consultation and Guidance, Kharazmi University, Tehran, Iran.
URL: https://psychologicalscience.ir/article-1-1278-fa.html
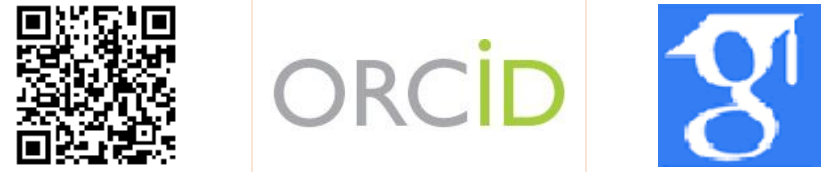

$\underline{10.52547 / J P S .20 .105 .1493}$

\section{A R T I C L E I N F O A B S T R A C T}

Keywords:

Acceptance and commitment therapy, Marital satisfaction, Self-efficiency, Cerebral palsy

Received: 27 May 2021 Accepted: 21 Jun 2021 Available: 22 Nov 2021
Background: Mothers of children with cerebral palsy are prone to social, economic, emotional and family pressures due to the presence of a child with cerebral palsy, which leads to a decrease in marital satisfaction and their perception of efficiency. Research has shown that acceptance and commitment therapy is a supportive approach that emphasizes the relationship and acceptance of individual and family values and uses awareness and acceptance along with commitment and behavior change strategies to increase psychological resilience that increases satisfaction. Couples and their self-efficacy, but there is a research gap in performing this intervention on mothers with children with cerebral palsy.

Aims: The aim of this study was to evaluate the efficacy of acceptance and commitment therapy based on increasing marital satisfaction and self-efficacy of mothers with children with cerebral palsy.

Methods: The present study is an applied research in terms of purpose and quasi-experimental in terms of data collection. The statistical population of the present study included all mothers with children with cerebral palsy who referred to educational and rehabilitation centers for the physically disabled in Kermanshah in 1399. The sample consisted of 23 volunteer mothers who were selected by convenience sampling method and randomly assigned to two experimental groups based on acceptance and commitment $(n=10)$ and a control group $(n=13)$. The experimental group received 12 sessions of 90-minute acceptance and commitment therapy according to Hayes (2008) approach once a week and the control group did not receive any intervention. Data were analyzed using Mixed analysis of variance.

Results: The results of repeated measures analysis of variance showed that acceptance and commitment-based therapy is effective in increasing marital satisfaction and self-efficiency of mothers with children with cerebral palsy. ( $\mathrm{P} \leq 0 / 001)$.

Conclusion: Based on the findings of this study, marital satisfaction and self-efficacy of mothers with children with cerebral palsy can be improved by using therapy based on acceptance and commitment.

* Corresponding Author: Esmail Asadpour, Assistant Professor, Department of Consultation and Guidance, Kharazmi University, Tehran, Iran.

E-mail: dr.iasadpour@khu.ac.ir

Tel: (+98) 9356769896

2476-5740/ (C) 2021 The Authors. This is an open access article under the CC BY-NC-ND license

(https://creativecommons.org/licenses/by-nc/4.0/). 


\section{Extended Abstract}

\section{Introduction}

Cerebral palsy is the most common motor disability and neurological complication in children and the immature brain. Its prevalence is reported to be approximately 2 to 3.6 person in 1000 live births, and indicating a high prevalence of this disorder (Påhlman, Gilberg, Wentz, \& Himmelmann, 2020; Boldirova, Striner, Rosenbaum, \& Ronen, 2020). By definition, any non-progressive damage to the central nervous system in the first two years of a child's life is called cerebral palsy. These children often also have various accompanying disorders and disabilities in the fields of cognition, emotion, behavior, and communication, which can usually create much more difficult conditions than motor disability alone (Jalili, Goodarzi, Rasafiani, Haghgoo, Dalvand, \& Farzi, 2013; Pahlman et al., 2020). Restrictions in activities lead to children's long-term dependence on caregivers and create special needs in the child that caregivers, especially mothers, must meet (Wang, Huang, \& Kong, 2020).

There is ample evidence that parents caring for children with disabilities have poorer physical and mental health outcomes than parents caring for healthy children, and these problems are far greater for mothers in particular (McCoy et al., 2020).

One of the potential problems is the decrease in marital satisfaction among parents, especially mothers. Marital satisfaction is the adjustment of the current situation to the expected situation. According to this definition, marital satisfaction is when the individuals' current situation in the marital relationship matches the situation they expect (Lee et al., 2020). In fact, marital satisfaction is a personal experience in the marital bond that can only be evaluated by the individual in response to the degree of enjoyment of the marital relationship, and many factors influence marital satisfaction in cohabitation, and this feeling plays a prominent role. It plays a role in the normal functioning of the family (Lee et al., 2019).

On the other hand, variables such as marital satisfaction, which is significant for mental health, physical and spiritual health, and quality of life of the family and its members (Yucel, 2017), may also directly or indirectly reduce parental engagement and cooperation. The involvement of mothers in the rehabilitation programs for their children has many and important effects on the quality of life and mental and physical well-being of children with disabilities as more vulnerable people and consequently on the quality of life of the whole family based on circular causation, which can also be mediated. Exacerbation of problems also reduces self-efficacy and marital satisfaction and even overall life satisfaction of mothers of these children (Edalati and Redzvan, 2010; Imani, Kazemi Rezaei, Pirzadeh, Valikhani, Kazemi Rezaei, 2015). Self-efficacy refers to the extent to which a person is confident in his or her ability to perform desired actions. In other words, self-efficacy is the certainty that a person has performed a particular behavior in a particular situation and expects the desired results (Pomaki, Karoly, and Maes, 2009).

There is ample evidence that parents caring for children with disabilities have poorer physical and mental health outcomes than parents caring for healthy children, and these problems are particularly prevalent among mothers (McCoy et al., 2020). One of these problems is marital satisfaction as a complex and multidimensional concept that is psychological in nature (Fallahchai, Fallahi, and Randall, 2019).

One of the duties of parents is to take care of the child, but if the child is functionally limited and dependent in the long term, this role will be different and will put a lot of pressure on mothers who usually play the role of caregiver. It comes. It can be said that a child's disability not only overshadows his or her life, but also affects the lives of caregivers and other family members, leading to health problems and reduced quality of life, and exposure to injuries. Such as decreased marital satisfaction and self-efficacy (Lee, Matthews, and Park, 2019).

The need and innovation of the present study is that today one of the most important issues in the public health system is the problems related to women and the family. When the family is facing problems beyond a normal family, such as having a child with cerebral palsy, - it can affect their psychological and social status in a way that leads to the breakdown of 


\section{Monthly Journal of Psychological Science}

the family system, in addition to the destruction of individual, professional and social performance. Therefore, the application of appropriate treatment methods for the members of these families, especially for the mothers as the main caregivers, can provide a clearer perspective to reduce the crisis that a cerebral palsied child causes in the family. Due to the knowledge gap in this area and the lack of research on the effectiveness of the treatment approach of acceptance and commitment among the variables mentioned and in society, as well as the need to achieve preferred interventions with greater effectiveness and cost efficiency due to sensitivity and prevalence. More physical disability and more double difficulty and limited resources to carry out the rehabilitation process in third world countries (Aminzadeh et al., 2018) and on the other hand, the possibility of preventing the loss of many family resources and societal costs as well as the reduction of important variables such as mental health, life satisfaction and family function, it is proposed that a new study is conducted on the effectiveness of groupbased acceptance and commitment therapy to increase marital satisfaction and self-efficacy of mothers with children with cerebral palsy. Therefore, this study aims to answer the question: Is acceptance and commitment therapy effective for marital satisfaction and self-efficacy of mothers with cerebral palsy children?

\section{Method}

The present study is applied research in terms of purpose and a quasi-experimental group of dissimilar groups in terms of data collection. The quasiexperimental design of the present study consisted of pre-test, post-test and follow-up with the control group. The statistical population of the present study included all mothers with cerebral palsy children who referred to educational and rehabilitation centers for
Vol. 20, No. 105, Autumn(December) 2021

physically disabled in Kermanshah in 1399. The sample of the study initially consisted of 26 volunteer mothers who were selected based on the results of the pretest (marital satisfaction and self-efficacy) and inclusion criteria and randomly divided into two experimental groups based on acceptance and commitment (13). And the control group (13 people) was replaced. The number of experimental groups was reduced to 10 due to various problems during the coronavirus epidemic, including difficulties in attendance and concern of some participating members.

\section{Results}

After testing the assumptions required to conduct a repeated measures analysis of variance, the data were analyzed using a repeated measures analysis of variance.

The results showed that the one-way analysis of variance in the repeated measures text was significant in terms of the effect of intervention (from pre-test to post-test) and intervention stability (post-test to follow-up) and the effect of time (pre-test to followup) on the dependent variables (marital satisfaction and self-efficacy are significant. According to the results of the effect of group on the variable scores of marital satisfaction $(\mathrm{P}<0.001, \mathrm{~F}=16.6)$ and selfefficacy ( $\mathrm{P}<0.001, \mathrm{~F}=9.914)$ means $\neg$ It was. Also, the effect of time and interaction of time $\times$ group on the variables of marital satisfaction and self-efficacy was significant. Therefore, it can be said that acceptance and commitment therapy based on the components of marital satisfaction and self-efficacy of mothers with children with cerebral palsy has been effective. In addition, the simple effect of the intergroup for the levels of the within-group factors was examined using the Bephneri correction. The results are shown in the following table.

Table 1. Benferoni test results (intragroup and intergroup) for comparison of acceptance and commitment based therapy and control group in pre-test, post-test and follow-up scores in dependent variables

\begin{tabular}{|c|c|c|c|c|c|}
\hline Variable & & ition & Mean difference & SD & $\bar{P}$ \\
\hline \multirow{2}{*}{ Marital Satisfaction } & \multirow{2}{*}{ Pre-test } & Post-test & $-16 / 67$ & $3 / 300$ & $\mathrm{P} \leq 0 / 001$ \\
\hline & & Follow up & $-17 / 45$ & $4 / 127$ & $\mathrm{P} \leq 0 / 001$ \\
\hline \multirow{2}{*}{ Self-efficacy } & \multirow{2}{*}{ Pre-test } & Post-test & $-6 / 908$ & $0 / 617$ & $\mathrm{P} \leq 0 / 001$ \\
\hline & & Follow up & $2 / 981$ & $0 / 986$ & $\mathrm{P} \leq 0 / 001$ \\
\hline \multirow{2}{*}{$\begin{array}{c}\text { Marital Satisfaction } \\
\text { Self-efficacy }\end{array}$} & $\mathrm{ACT}$ & Control & 19 & $4 / 661$ & $\mathrm{P} \leq 0 / 001$ \\
\hline & $\mathrm{ACT}$ & Control & $8 / 654$ & $2 / 748$ & $\mathrm{P} \leq 0 / 005$ \\
\hline
\end{tabular}




\section{Monthly Journal of Psychological Science}

The Benfroni correction level results showed that there was a significant difference between the experimental and control groups on the posttest and follow-up variables related to marital satisfaction and self-efficacy ( $\mathrm{P} \geq 0.001)$. In other words, considering the significance of the Benferoni test when comparing the pairs of pretest-posttest (intervention effect), posttest-follow-up (intervention stability), and pretest and follow-up (time effect) pairs between case groups Study (experimental and control group) and position (pretest, posttest, and follow-up) There is a difference in marital satisfaction and self-efficacy scores $(\mathrm{P} \geq 0.001)$. In other words, participants in the experimental group had an increasing linear trend in marital satisfaction and self-efficacy scores.

\section{Conclusion}

The results showed that acceptance and commitment therapy increased marital satisfaction in the experimental group compared to the control group.

These results are consistent with the findings of other studies (Rachael, 2018; Hosseini et al., 2019 and Ahmadi and Raisi, 1398) that individuals whose acceptance and commitment therapy is effective increase marital satisfaction. Also, in the study of Esfandiari Bayat et al. (1400) in a study concluded that despite the differences in content and process of the two approaches of rational-emotive behavior therapy and therapy based on acceptance and commitment, elements such as emotional discharge, hope and universality of human experience In both treatments, it increases the forgiveness of women.

To explain these results, it can be said that one of the skills taught in the therapeutic approach of acceptance and commitment was the expression of feelings and values based on committed action, which increases the satisfaction and closeness of couples. An important factor during the therapy sessions was the promotion of positive behaviors that increase intimacy in the couple relationship. Emphasis was placed on ensuring that these positive intimate behaviors are not performed unilaterally by people who lack the skills of nonjudgment, mindfulness, acceptance, and engagement. They use linguistic values in the context of relationships, they feel more control over the situation and living conditions, and
Vol. 20, No. 105, Autumn(December) 2021

this also increases marital satisfaction (Griffiths et al., 2018).

The results also showed that acceptance and commitment therapy increased the self-efficacy of the experimental group compared to the control group. These results are consistent with the findings of other studies (Rachael, 2018; Hosseini et al., 2019 and Ahmadi and Raisi, 1398) that people whose acceptance and commitment therapy is effective increase their self-efficacy.

To explain the results, it can be said that a large part of the skills taught in the therapy group is based on acceptance and commitment, living valuable and accepting negative emotional states, and paying attention to the person's internal states (such as emotion and cognition). Is in a non-judgmental and receptive state. Using mindfulness skills during training allows people to reduce habitual and spontaneous responses to stressful experiences. Eventually, the person's feedback and insight expands, and the person accepts life's unchanging events, reducing stress responses. In this way, a physical and mental calmness emerges in the person, which provides the basis for increasing social, emotional, and psychological self-efficacy (Lillis and Kendra, 2014).

\section{Ethical Considerations}

Compliance with ethical guidelines: This research has been approved in Kermanshah University of Medical Sciences with ethics ID IR.KUMS.REC.1399.776. The license for the present study was issued to the studied group from the Welfare Department of Kermanshah with the letter number 4595/14/99/730. All participants received written information about the research and participated in the research if they wished; People were reassured that all information was confidential.

Funding: This study was conducted as a $\mathrm{PhD}$ thesis with no financial support.

Authors' contribution: The first author is the main researcher of this research. The second author is the supervisor and the third author is the consultant professor of the dissertation.

Conflict of interest: the authors declare no conflict of interest for this study.

Acknowledgments: I would like to thank the supervisors and advisors of this research, as well as the research department staff, Kermanshah Medical Sciences and the Welfare Department of Kermanshah who assisted us in conducting this research. 


\section{اثربخشى درمانكرى مبتنى بر يذيرش و تعهد بر رضايت زناشويى و خود كار آمدى مادران داراى فرزندان با فلج مغزى}

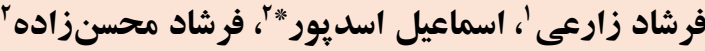

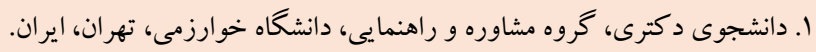

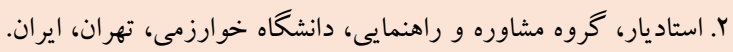

ous

زمينه: مادران كو دكان با فلج مغزى به دليل وجود كود كك مبتلا به فلج مغزى، مستعد فشارهاى اجتماعى، اقتصادى، هيجانى و خانوادىى آنى

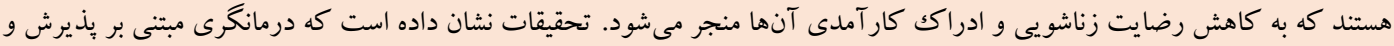

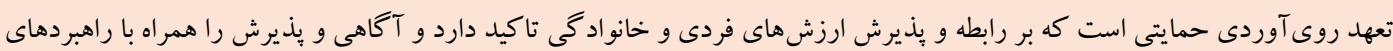

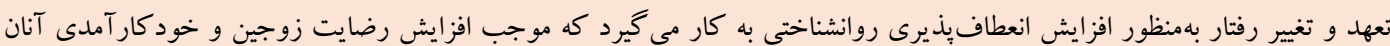

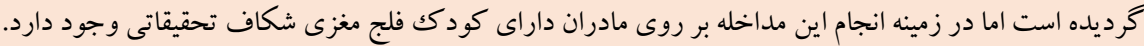

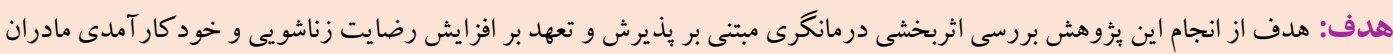
داراى فرزندان با فلج مغزى بود.

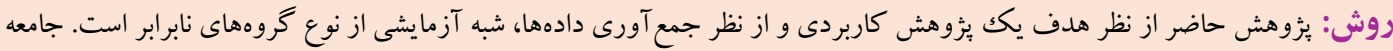

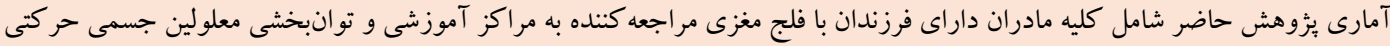

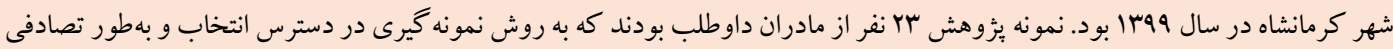

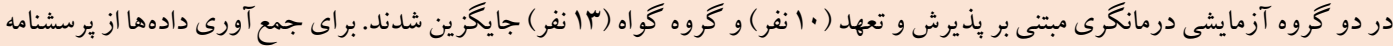

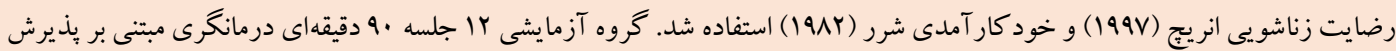

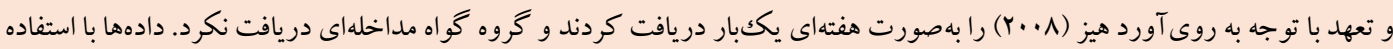
از آزمون تحليل واريانس مختلط تحليل شدند.

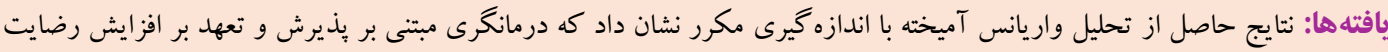

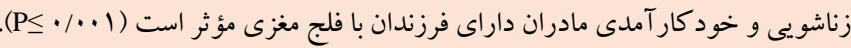

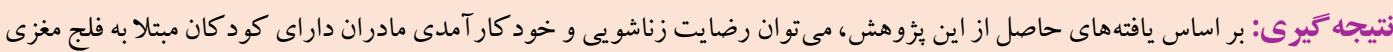

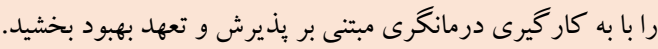

مشخصات مقاله

كليدوازهها: درمانخرى مبتى بر بذيرش و تعهل،

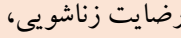

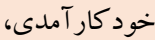

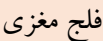

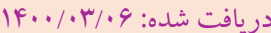

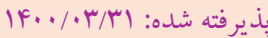

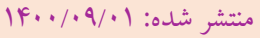

* نويسنده مسئول: اسماعيل اسديور، استاديار، گروه مشاوره و راهنمايى، دانشكاه خوارزمى، تهران، ايران. رايانامه: dr.iasadpour@khu.ac.ir

تلفن: 
شخصى، ارتباط، حل تعارض، مديريت مالى، فعاليت اوقات فراغت، رابطه جنسى، فرزندان، دوستان و جهت گيرى مذهبى وابسته است (فلاحجى، ملاطي،

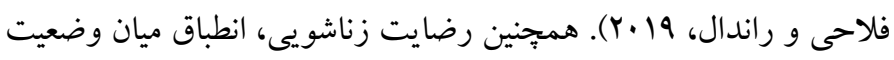
موجود با وضعيت مورد انتظار است؛ طبق اين تعريف، خوشنودى زناشويى

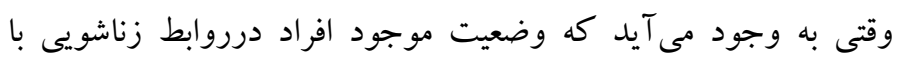

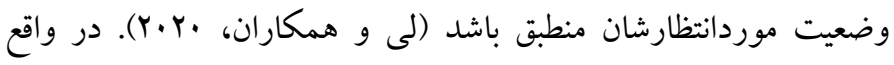
رضايت زناشويى يكك تجربهى شخصى در بيوند زناشويى است كه تنها

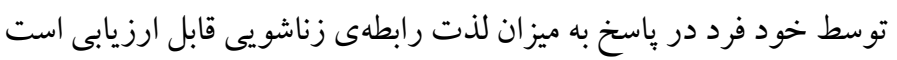

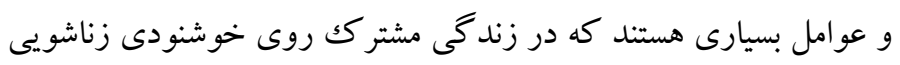

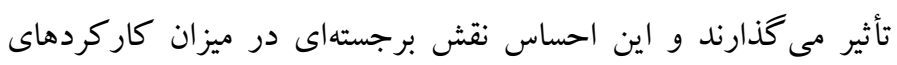

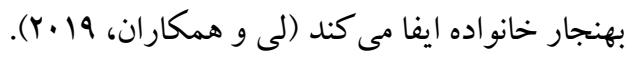

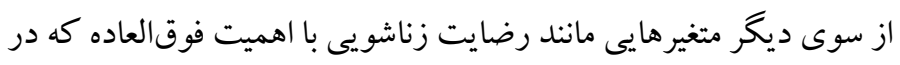
سلامتروانى و سلامت جسمانى و رواندرستى و كيفيت زندگى خانو اده

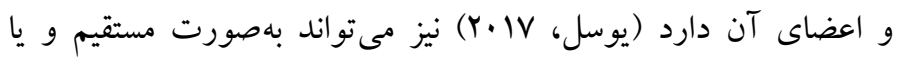

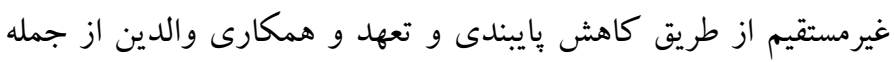

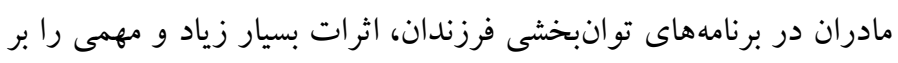
كيفيت زندگى و رواندرستى روانى و جسمانى فرزندان معلول بهعنوان

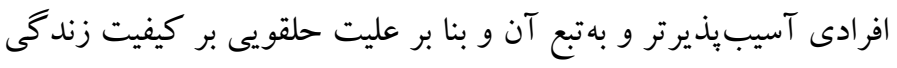

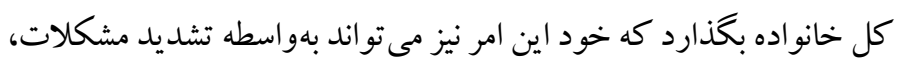

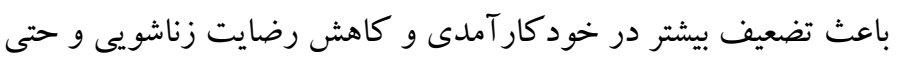

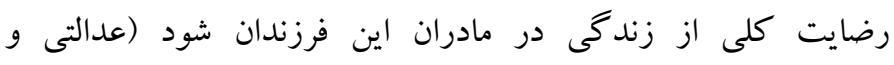

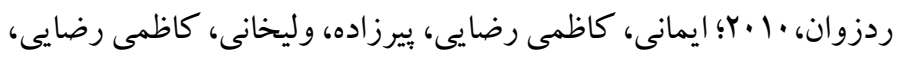

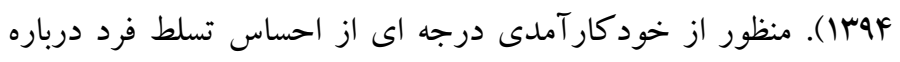

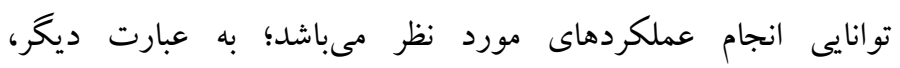

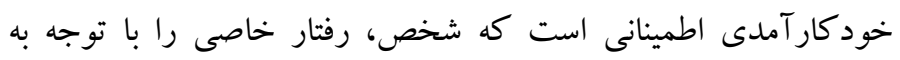

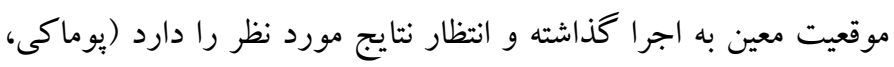

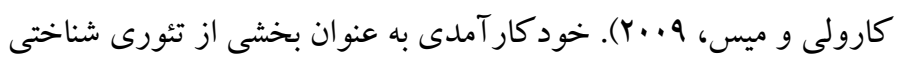

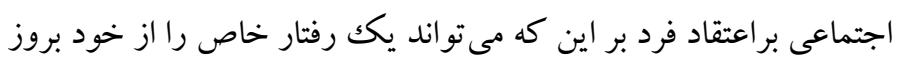

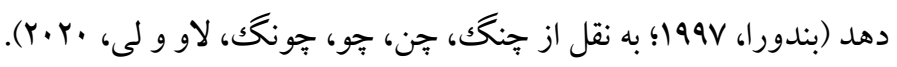

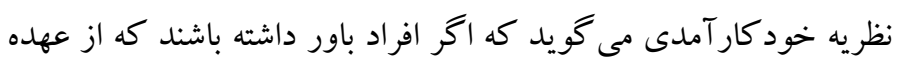

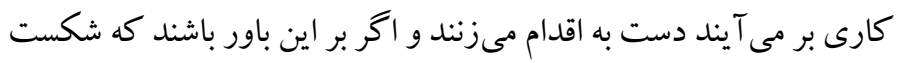

\section{Handicap}

dolقo

فلج مغزى' شايع ترين ناتو انى حر كتى و عارضه عصب شناختى در كود كان

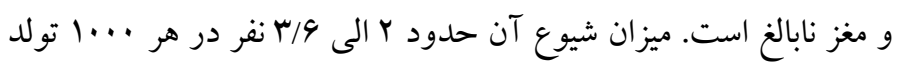
زنده گزارش شده است كه بيانكر شيوع بالاى اين اختلال است (يلهان،

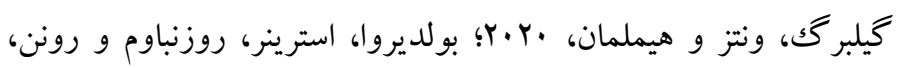
.r.Y. مركزى طى دو سال اول زندگى كودكى، فلج مغزى ناميده مى شود.

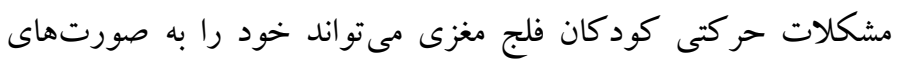

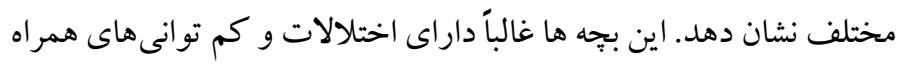

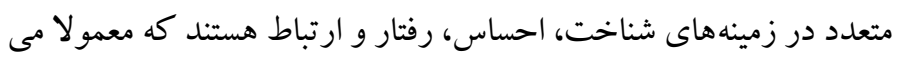

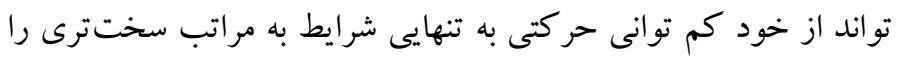

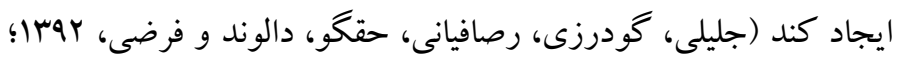

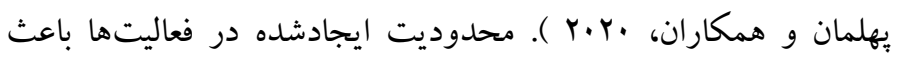

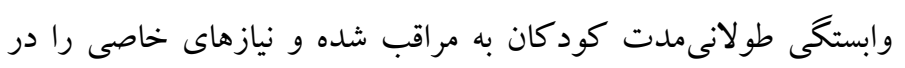

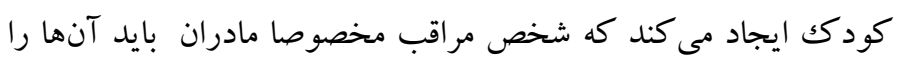

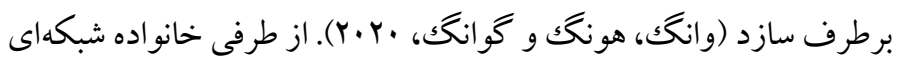

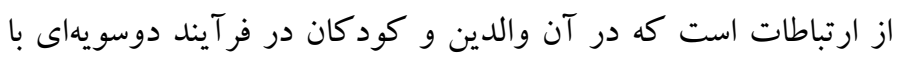

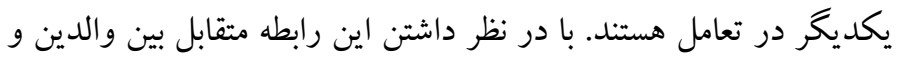

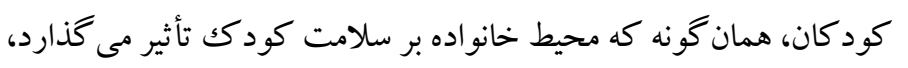

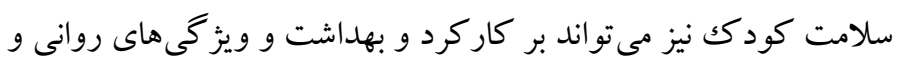

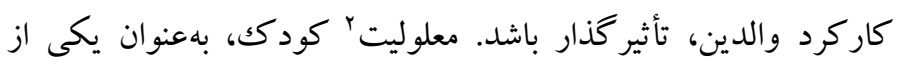

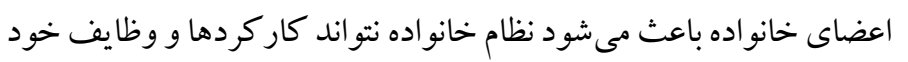
را به نحو مطلوب انجام دهد، در نتيجه در كاركرد اعضا و كليت خانواده اشكالاتى به وجود مى آيد (بولديرواو همكاران، ·r.r. (Y). شواهد بسيارى وجود دارد كه نشان مىدهد والدينى كه از كود كان ناتوان

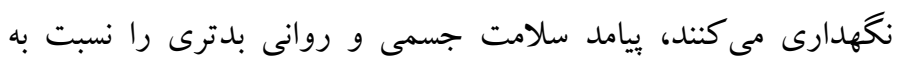
والدينى كه از كودكان سالم نخهدارى مى كنند، تجربه مى كنند كه اين مشكلات به ويزه در مادران به مراتب بيشتر است (مكك كوى و همكاران، .Y.Y.

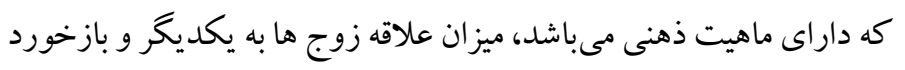
مثبت به متأهل بودن است كه با عواملى از جمله تحريف آرمانى، مسائل

1. Cerebral Palsy 
هاى آموزشى و تمر كز بر رضايت زناشويى مادران در صدد بوشش دادن

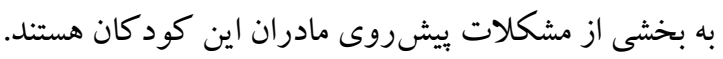

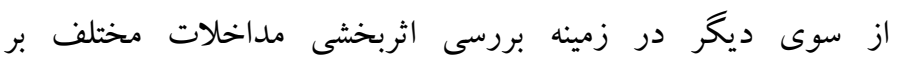

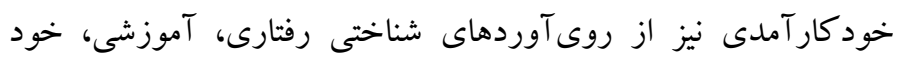

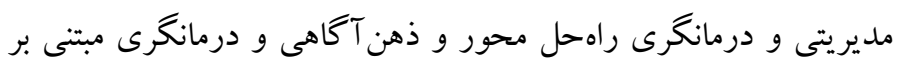
يذيرش و تعهد' استفاده شده است (باقرى، سعادتى، فتح اللهزاده و دربانى،

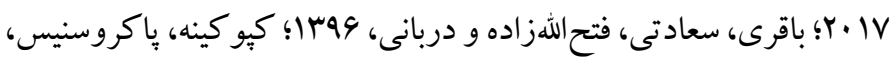

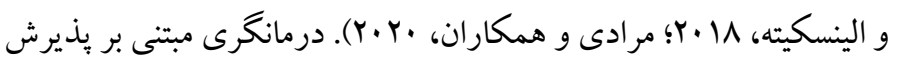

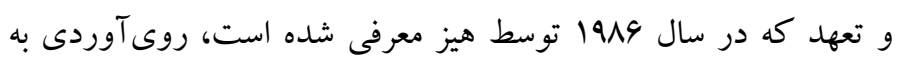

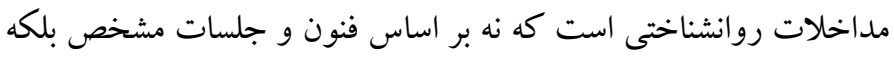
بر اساس فر آيندهاى نظرى معينى تعريف مىشود. اين روى آورد بهعنوان

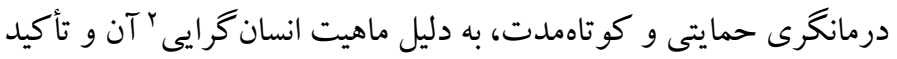

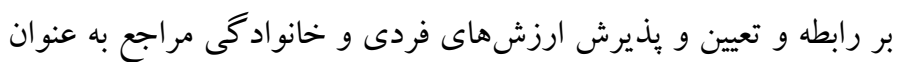

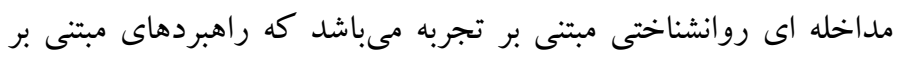

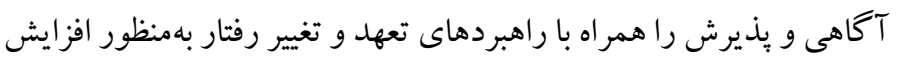

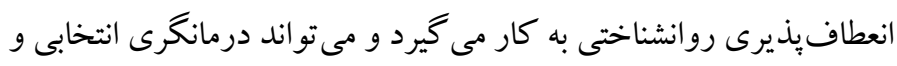

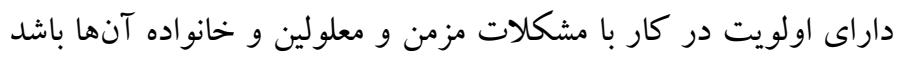

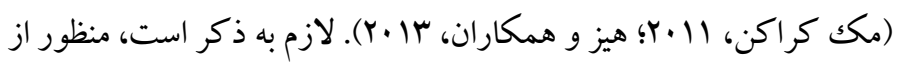

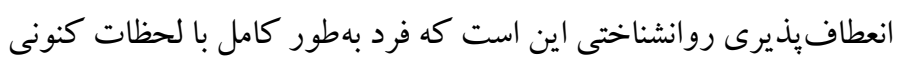
تماس داشته و بر اساس مقتضيات وضعيتى كه در آن قرار دارد متعهد شود

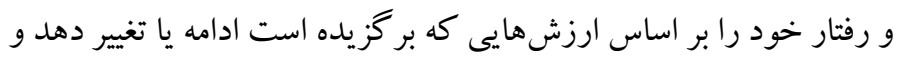

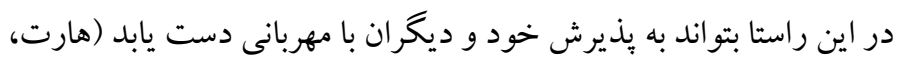

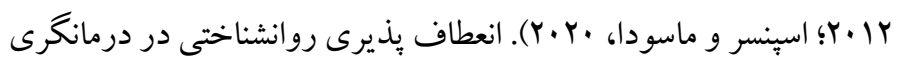
مبتنى بر بذيرش و تعهد از طريق شش فر آيند اصلى و زيربنايى ايجاد

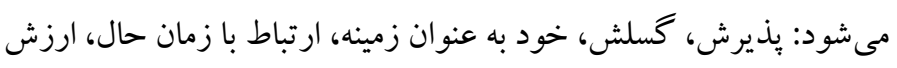

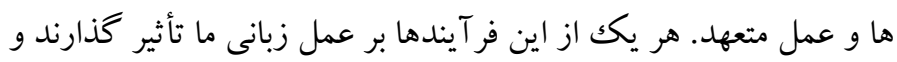

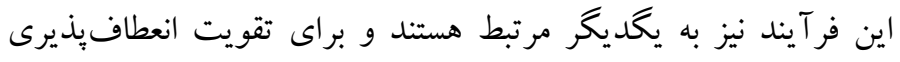

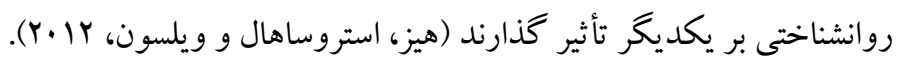

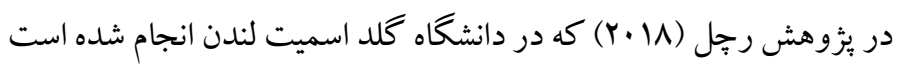

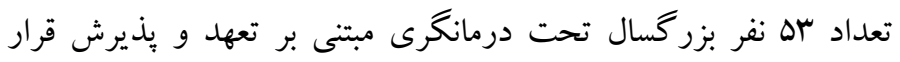

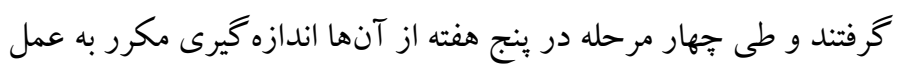

\section{Humanism}

مىخورند از آن برهيز مى كند (تو كاس، هايدن، مكك گراته، هو زز و

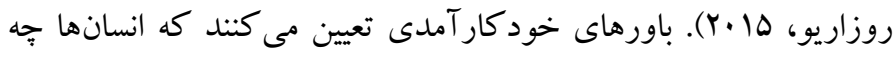

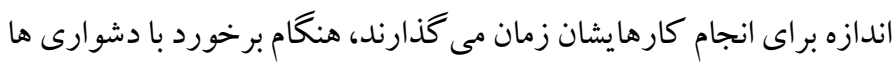

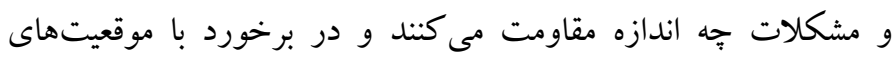

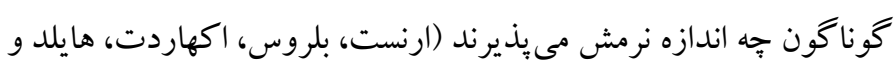

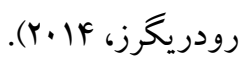
يكى از وظايف والدين، مراقبت از كودك است ولى زمانى كه كودكك از

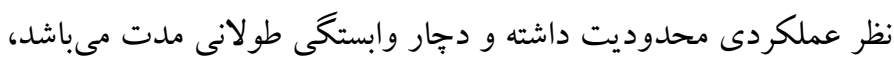

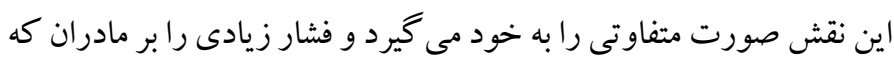

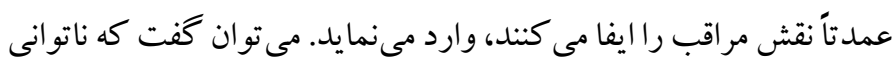

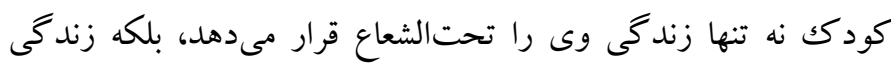

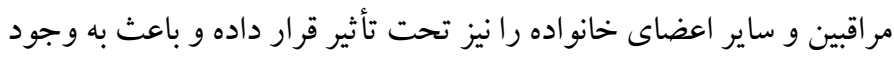

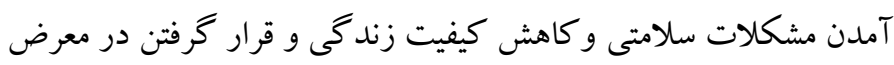

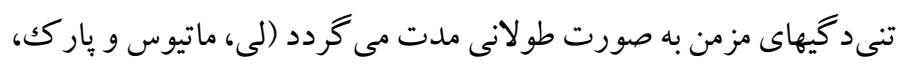

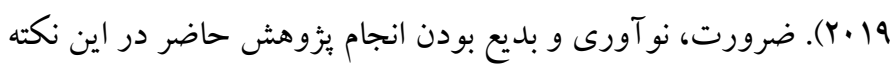

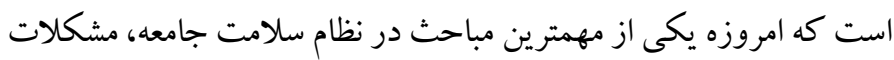

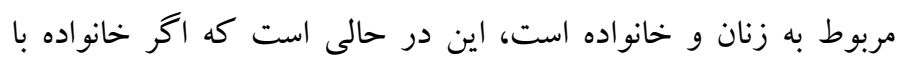

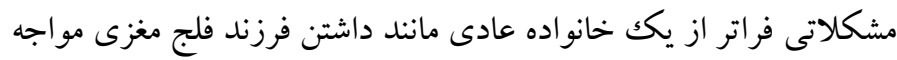

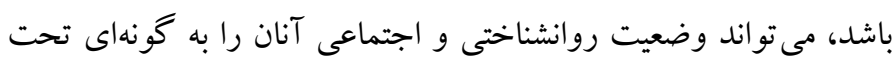

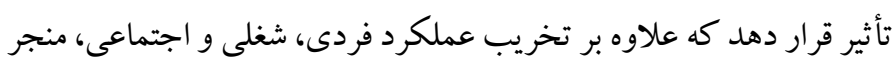

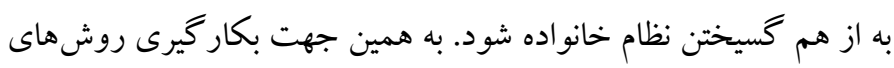

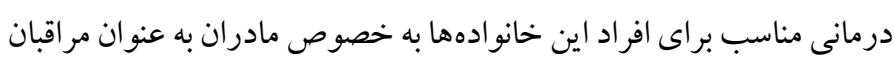

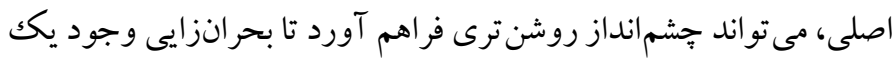

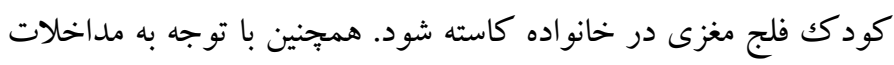

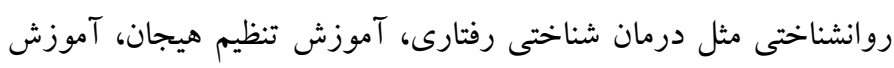

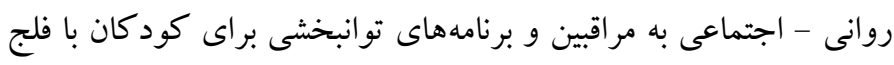

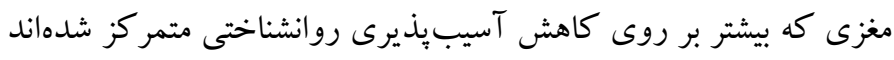

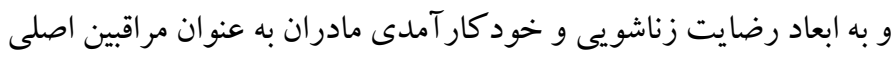

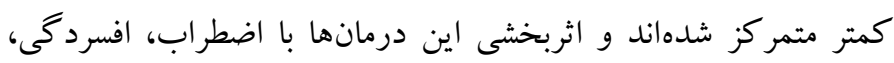

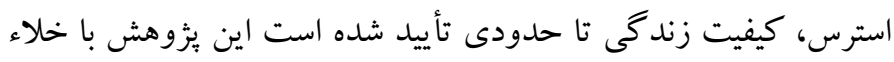

1. Acceptance and Commitment-Based Therapy (ACT) 
خود كار آمدى مادران داراى فرزندان با فلج مغزى انجام يذيرد. مسئله حائز

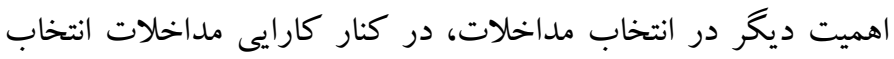

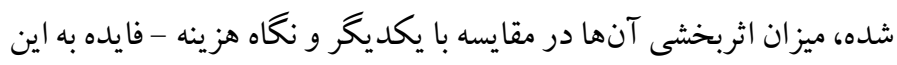

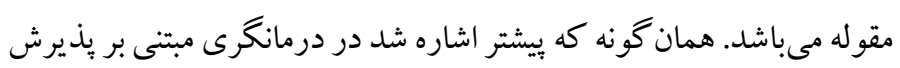

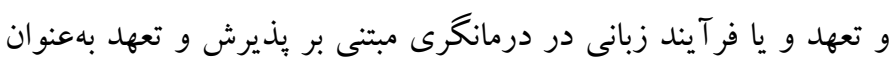

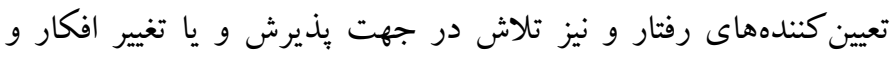

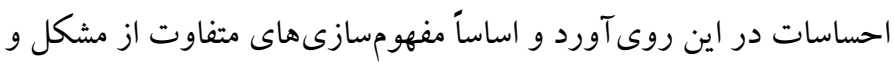

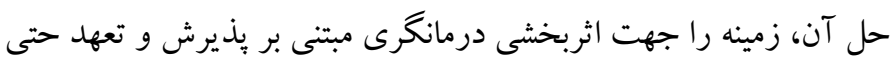

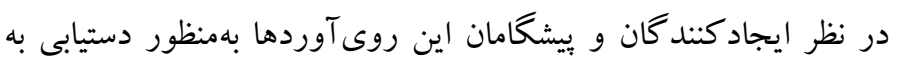

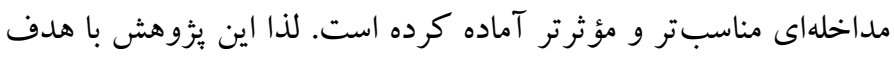

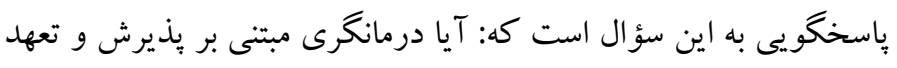

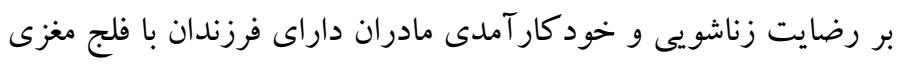

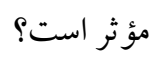

روش

الف) طرح ئوهش و شر كت كنند كان: ئزوهش حاضر از نظر هدف

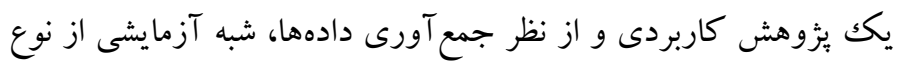

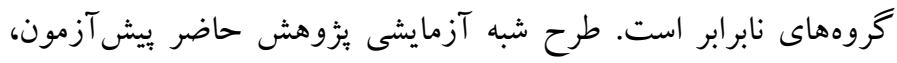

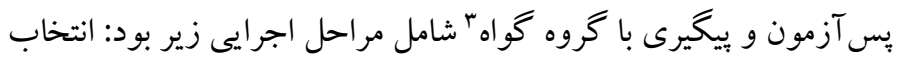

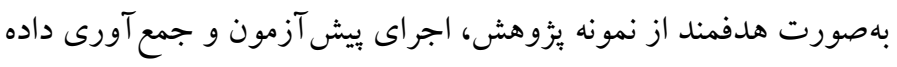

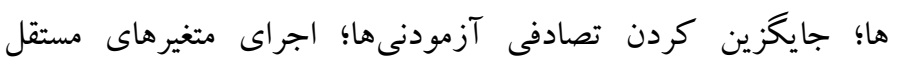

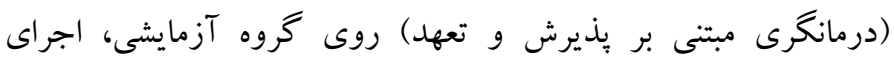

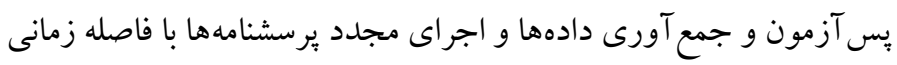

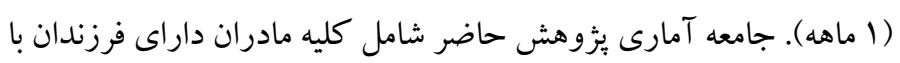
فلج مغزى مراجعه كننده به مراكز آموزشى و توانبخشى معلولين جسمى

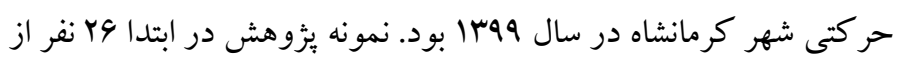
مادران داوطلب بودند كه بر اساس نتايج ناشى از ييش آزمون (رضايت

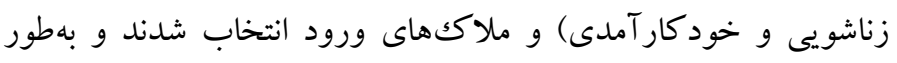

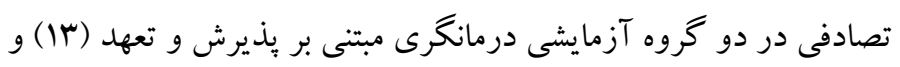

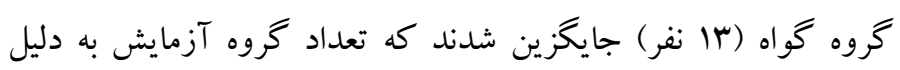

${ }^{3}$. The pretest-posttest control and follow-up group design
آمد. نتايج مطالعه نشاندهنده تغييرات معنىدار در متغيرهاى سلامتروانى

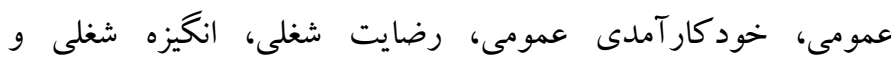

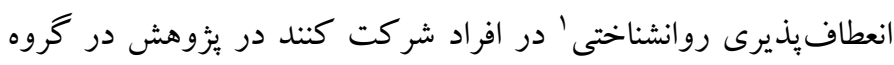

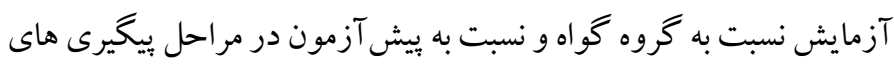

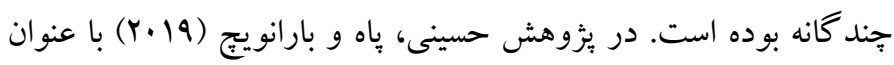

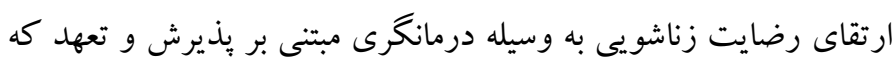

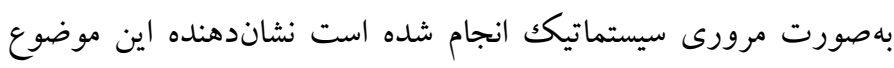

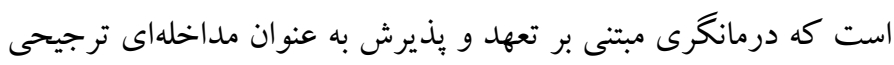

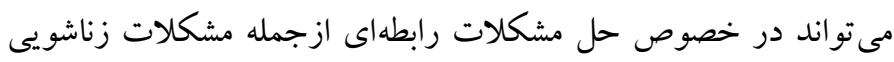

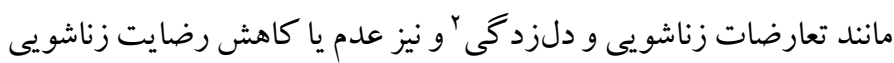

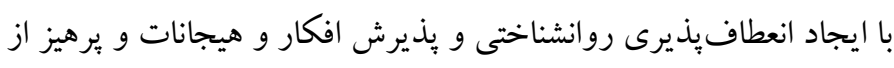
اجتناب تجربى بهصورت معنادارى اثربخش باشد و در زوجين داراى بلدي مشكلات مختلف زناشويى به نحو مناسبى مورد استفاده قرار گيرد. همجينين

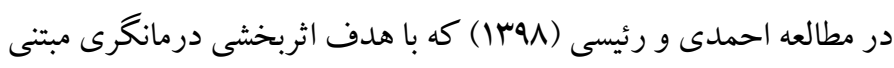

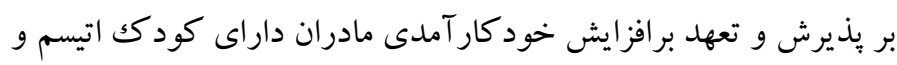

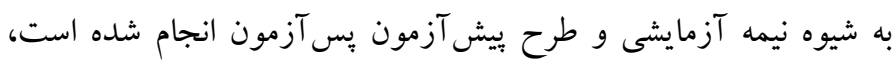

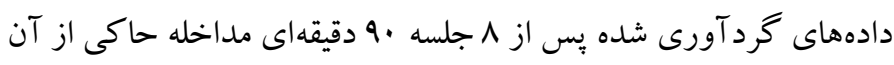

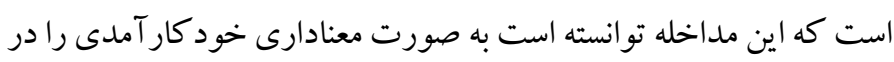

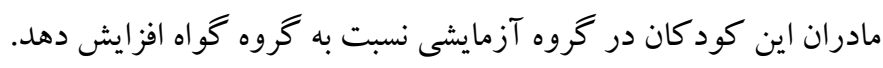

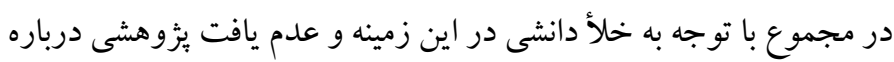

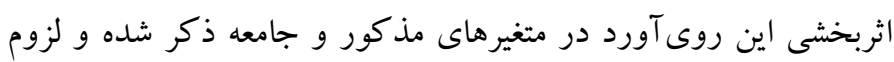

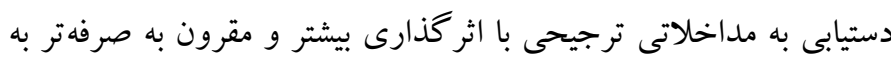

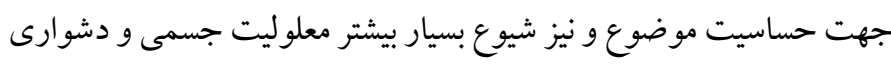

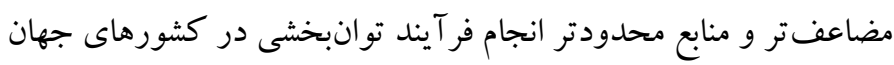

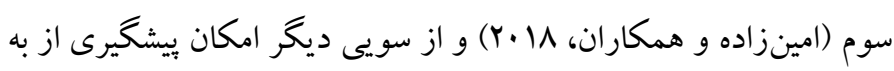
هدر رفتن بسيارى از منابع خانواده و نيز هزينهاى جامعه و همجينين

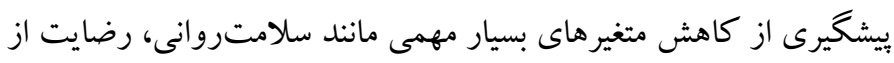

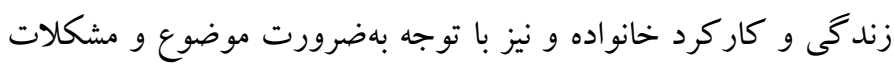

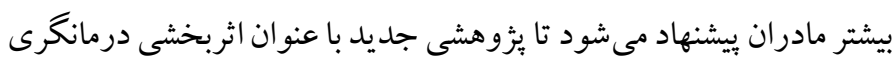

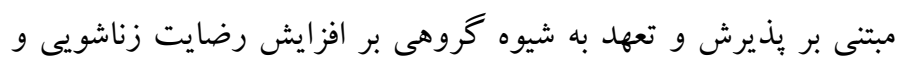

1. Psychological flexibility

2. Burnout 
در اين بثوهش جهت كسب رضايت از آزمودنى هاى مطالعه، از بيانيه هلسينكى ' كه حامى و يشتيبان اساسى قو ائد اخلاقى يزوهش است، استف استفاده

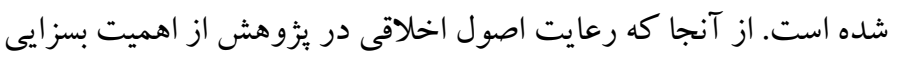
برخوردار است، در انجام مطالعه حاضر نيز موارد زير در نظر كرفته شداصد

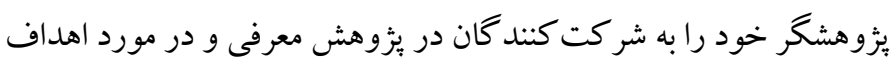

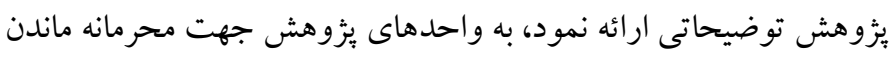

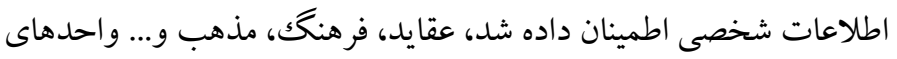

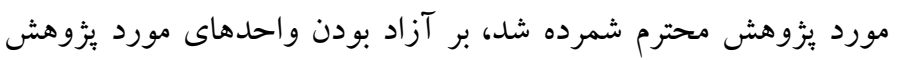

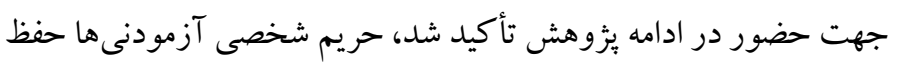
شد و به آنها در مورد بى خطر بودن مداخله اطمينان داده شد، در ثبت

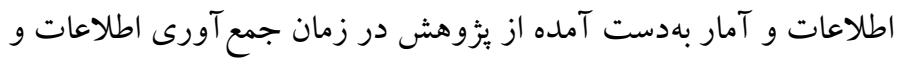
تجزيهو تحليل آنها و استفاده از منابع دقت و امانتدارى عملى به عمل

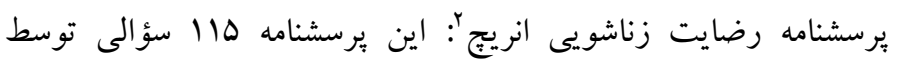

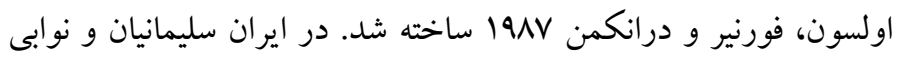

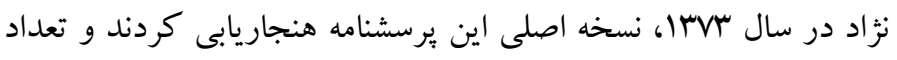

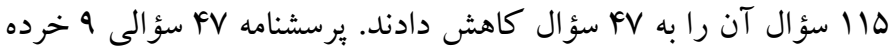
مقياس موضوع هاى شخصيتى را با سؤالهاى Y، F، r Iا، r و و •F، ارتباط

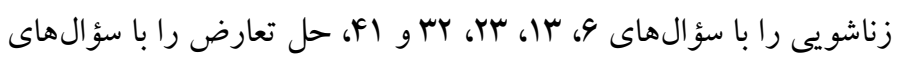

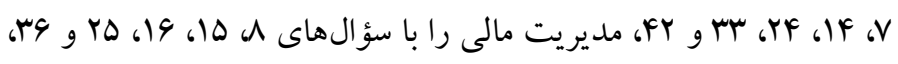

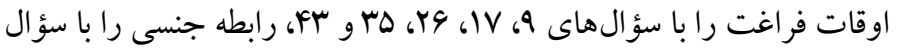

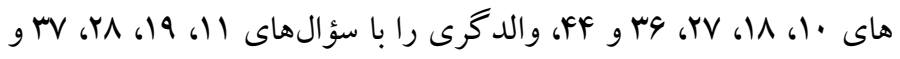

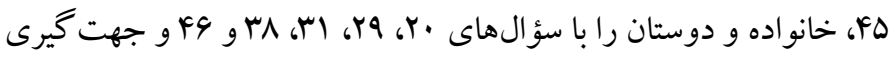

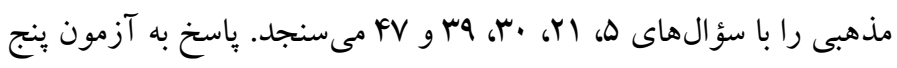

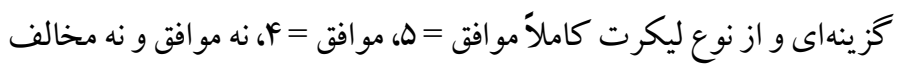

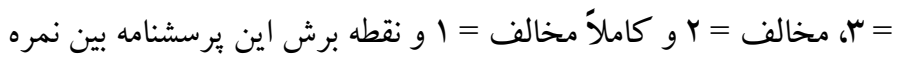

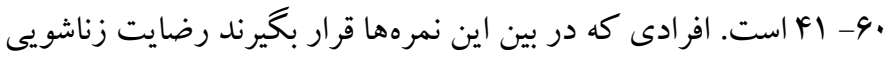

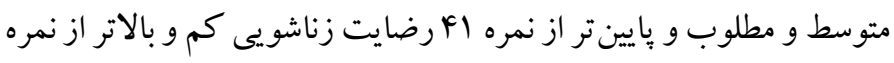

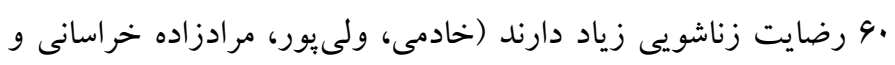

2. Enrich Marital Satisfaction Questionnaire
مشكلات مختلف دوران همه گيرى كرونا از جمله دشوارى در حضور و نخر انى برخى اعضاى شر كت كننده، به · انفر تقليل ييدا كرد. بدين صورت

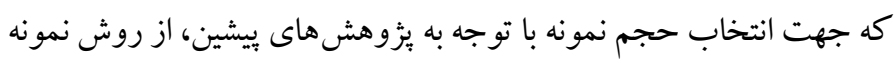
گيرى غير احتمالى در دسترس و هدفمند با گمارش تصادفى بين گرووها

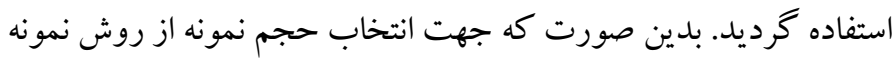
گيرى غيراحتمالى در دسترس و هدفمند با گمارش تصادفى بين گروههاب

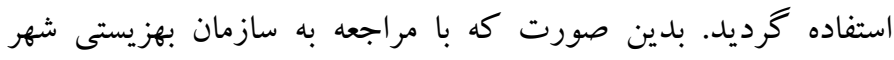

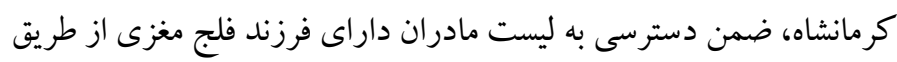

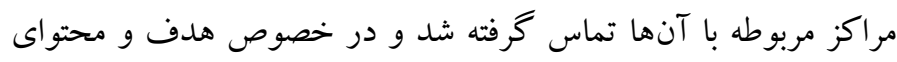

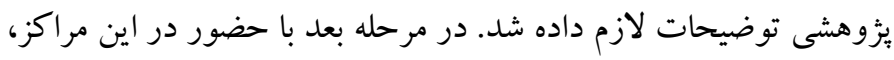

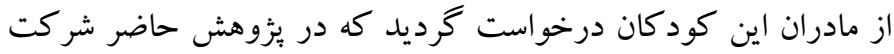

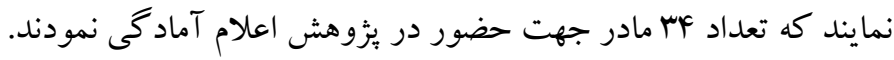
سبّ بر سشنامههاى رضايت زناشويى و خود كار آمدى به اين مادران ارائه

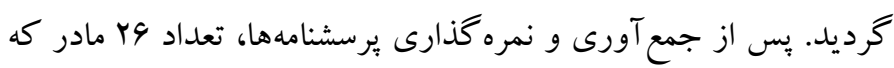

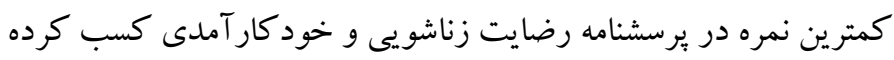
بودند، انتخاب و پِ از دعوت جهت شركت در يُروهش به صورت

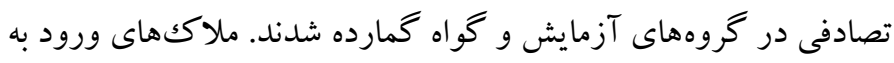

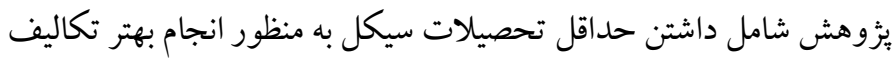

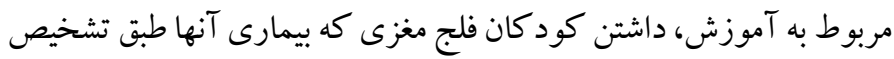

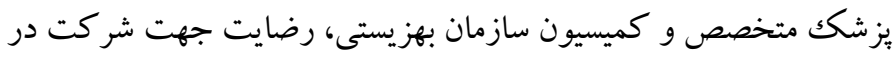
يُزوهش و داشتن سلامت جسمى (با توجه به يرونده سلامت و مشاورهاى

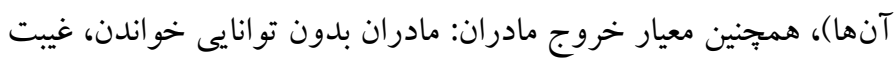

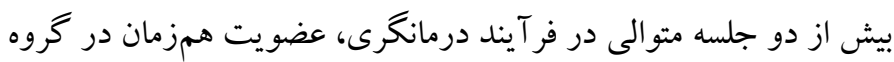

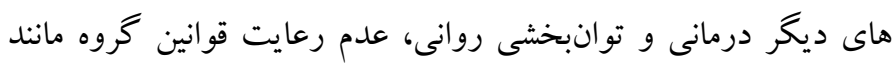

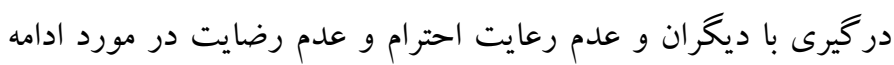

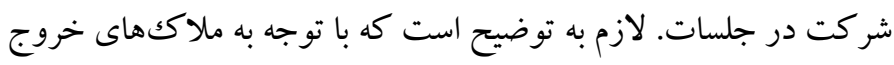

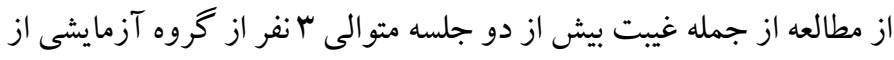

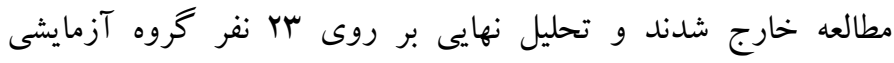

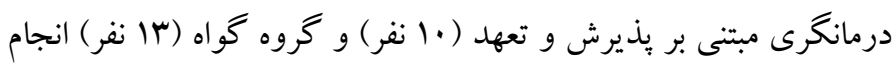


توضيحات مقدماتى، مفهومسازى مشكل، آمادهسازى مر اجعين، آشنايى با

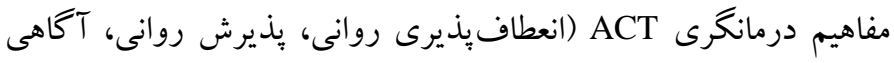
روانى، جداسازى شناختى، خودتجسمى، داستان شخصى، روشنى سازى

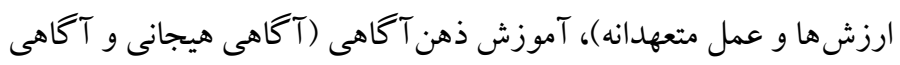
خردمندانه) بود. شيوه اجراى مداخله به اين شكل بود كه محقق ابتدا مجوزهاى لازم جهت برد

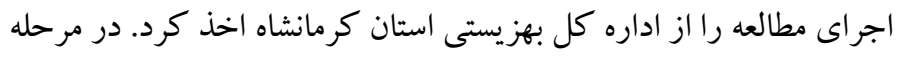

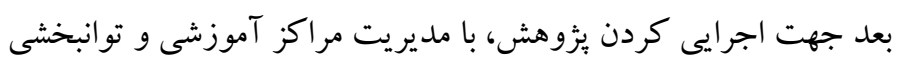

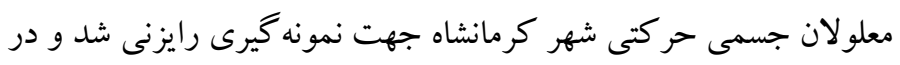

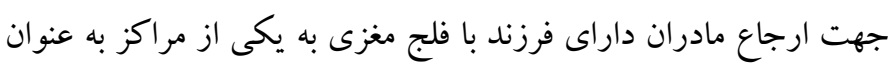

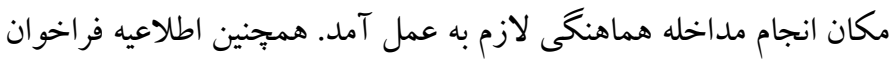

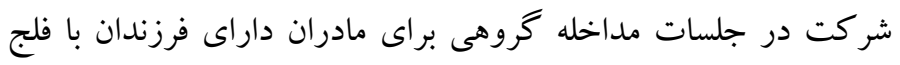

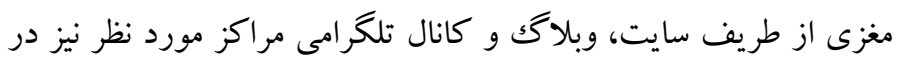

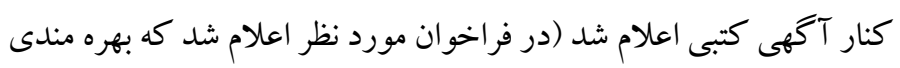
از جلسات و رفت و آمد رايگان خواهد بود). در مرحله بعد از متقاضيان

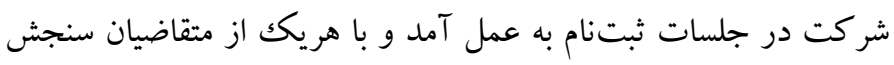

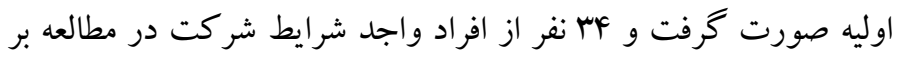
اساس ملاكك هاى ورود و خروج يزوهش به شيوه هدفمند انتخاب شدند.

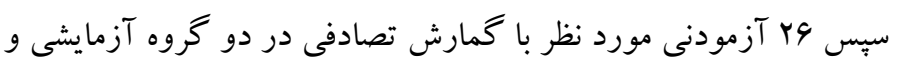

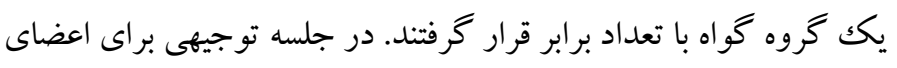

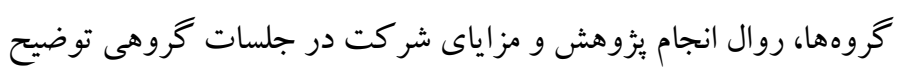
داده شد و سبس جهت سنجش موارد مورد نظر محقق، تمامى شركت روت

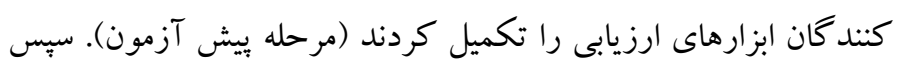

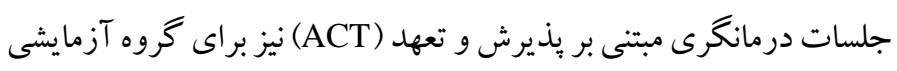
در سا جلسه •و دقيقهاى با توالى هر هفته يكك جلسه در محل تو بافق و تعيين

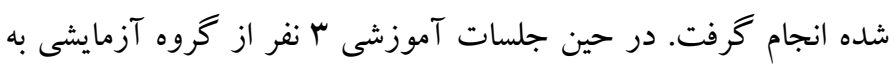

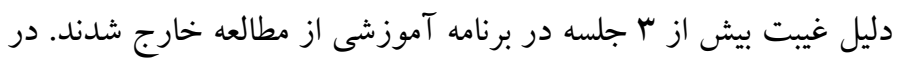

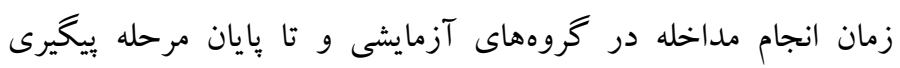

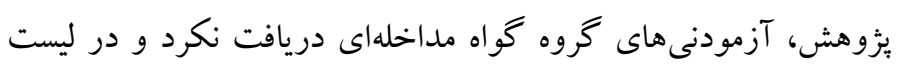

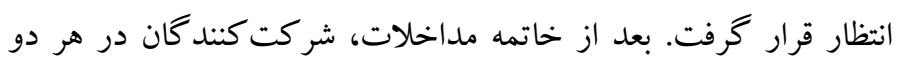

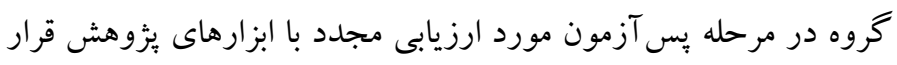

نيشابورى، سوس (1). قابليت اعتماد نسخه اصلى 110 سؤالى اين يرسشنامه با روش ضريب آلفاى كرونباخ توسط اولسون و همكاران در سال 191VV Y / • و قابليت اعتماد نسخه كو تاه شده توسط سليمانيان و نو ابعنز اد در سال

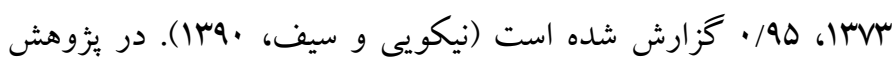

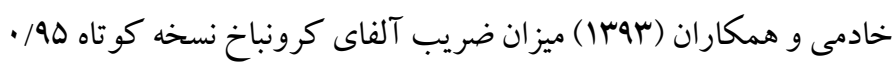
به دست آمد. ير سشنامه خود كار آمدى' (SES): اين يرسشنامه توسط شرر و همكارانش

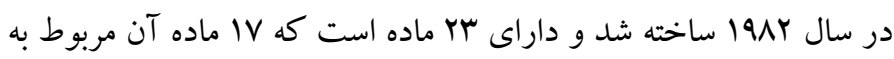

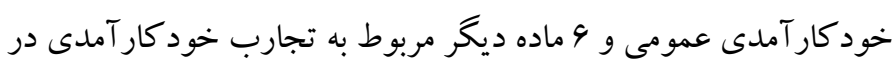

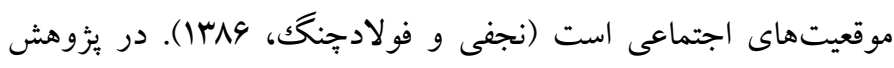

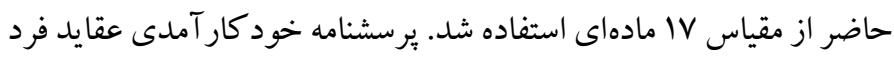

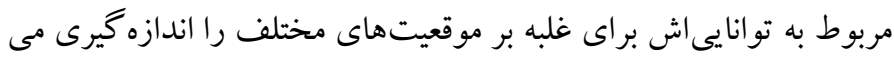

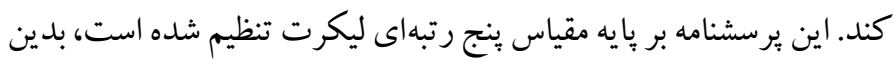

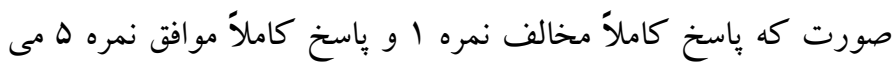

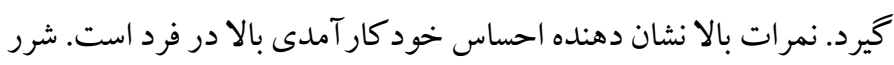

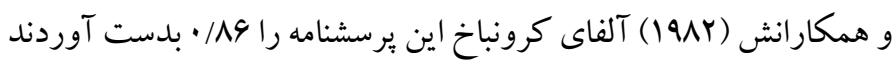
و براى سنجش قابليت اعتماد سازه مقياس خود كار آمدى ازهمبستخى آن

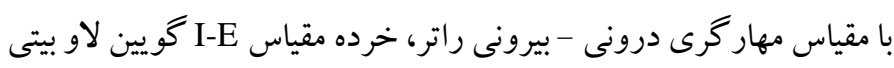

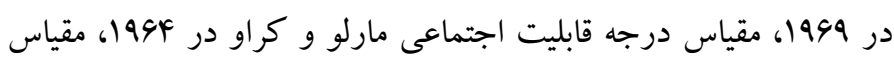

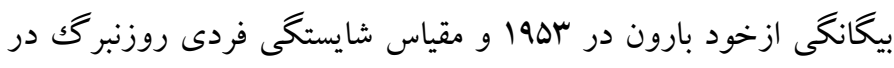

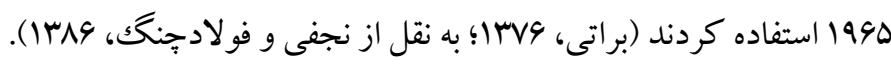
بر اساس بررسى هاى انجام شده بين نمرات خودكار آمدى و مقياس

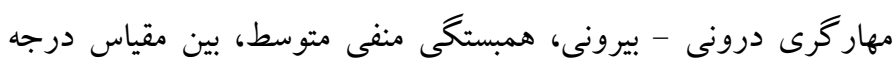

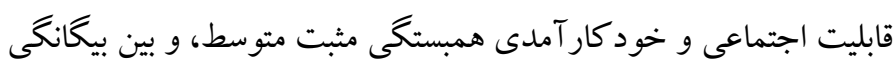

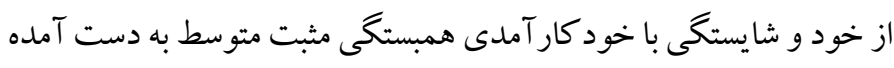

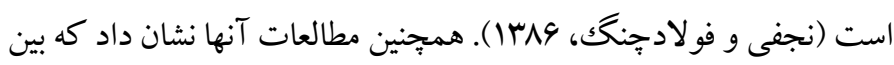

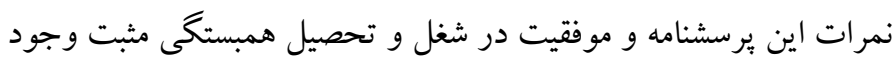

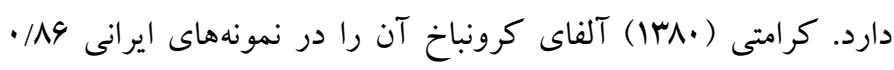

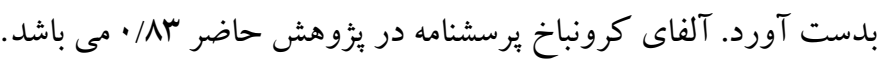
برنامه آموزش يذيرش و تعهل: آموزش يذيرش و و تعهد (هيز و همكاران،

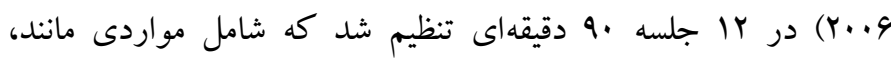

${ }^{1}$. Self-efficacy Scale (SES) 


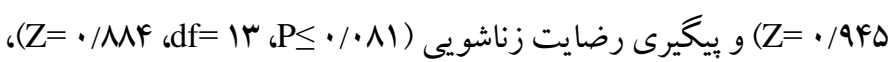

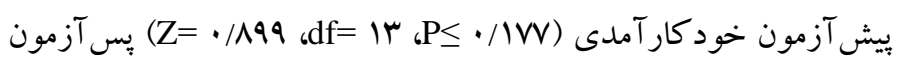

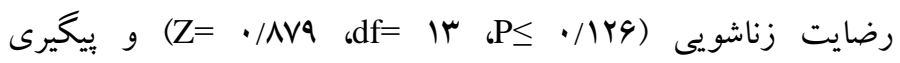

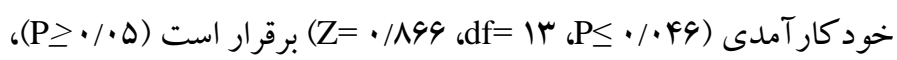

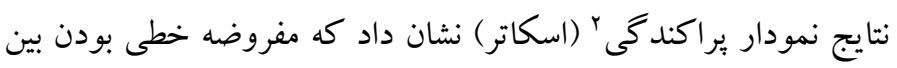

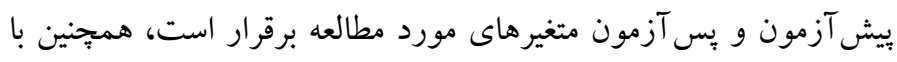

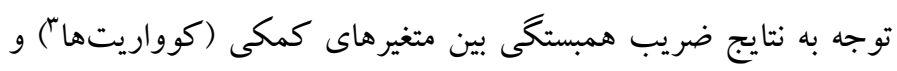

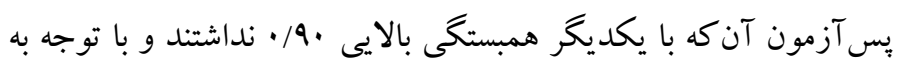

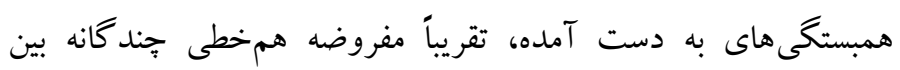

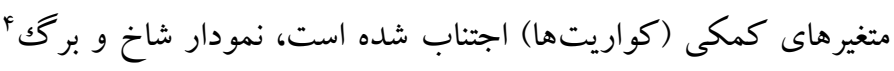
نشان داد كه در مرحله بيش آزمون، پِ آزمون و وبيخيرى نمرهاى در كرانه

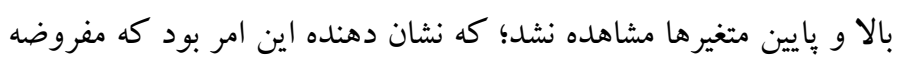

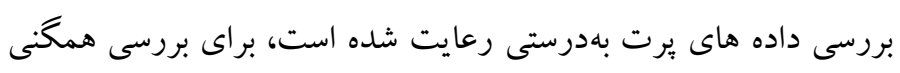

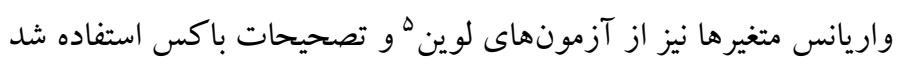

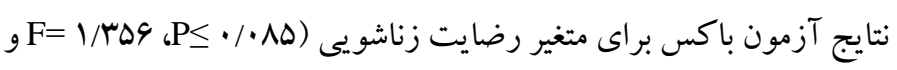

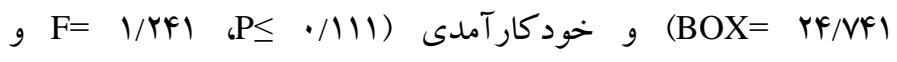
كه ميز ان معنادارى آزمون باكس از ه • (BOX=19/9V. نتيجه فرض مربوط به همخنى ماتريس هاى واريانس - كوواريانس، بذيرفنه

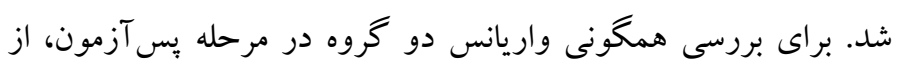

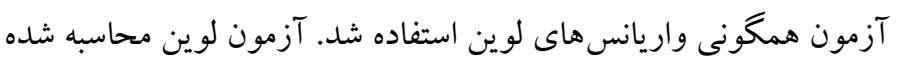

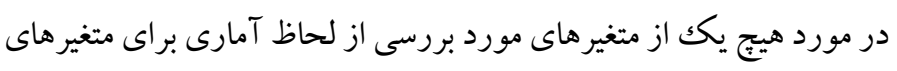

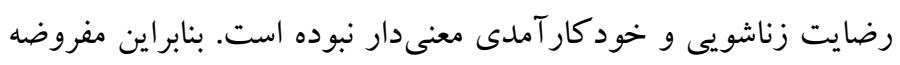

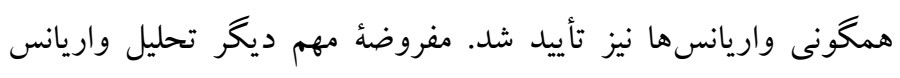

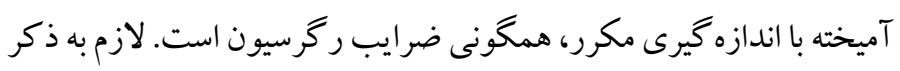
است كه آزمون همخونى ضرايب رگرسيونى از طريق تعامل بيش آزمون نمرات متغيرهاى رضايت زناشويى و خود كار آمدى با متغيرهاى مستقل

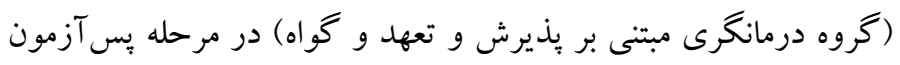

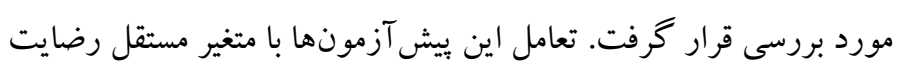

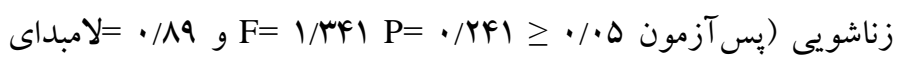

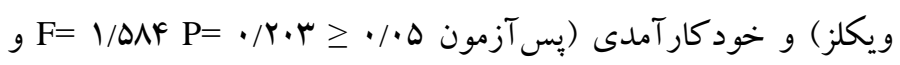

4. stem \& leaf

5 . Leven's test of equaility variances
كرفتند. يكك ماه بِ از بايان مرحله بِ آزمون نيز جهت سنجش ماند كارى

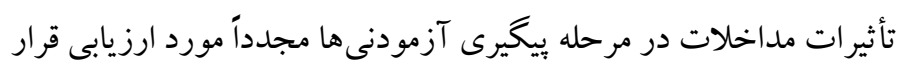

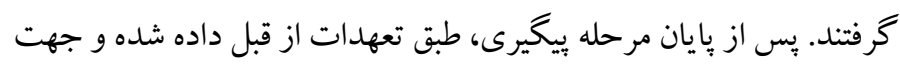
رعايت اخلاق حرفه ای، ضمن قدردانى از همكارى گروه گو اه، مداخلات مذكور براى آنها نيز انجام گرفت

يافته ها بررسى داده هاى حاصل از الطلاعات جمعيت شناختى نشان داد كه ميانخين

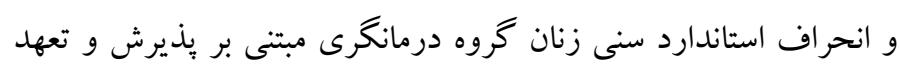
r

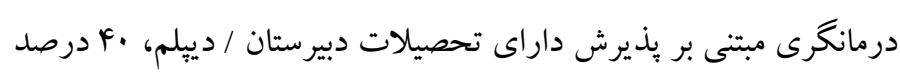

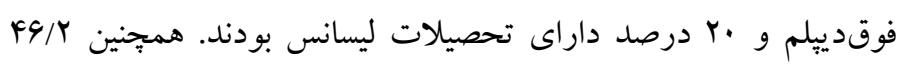

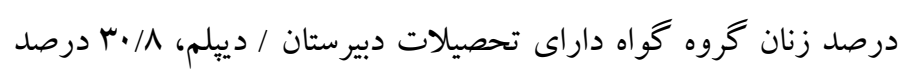

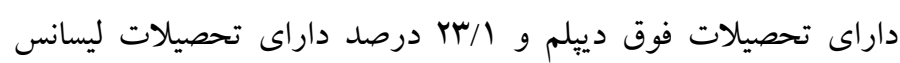

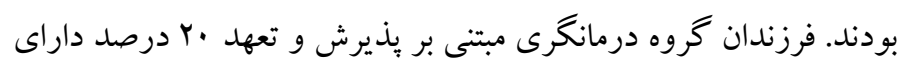

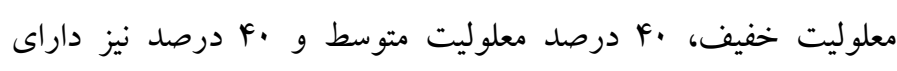
معلوليت شديد بودند. همجينين V/V درصد از فرزندان مادران خروه كوراه

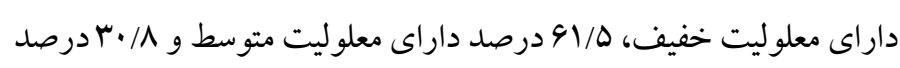

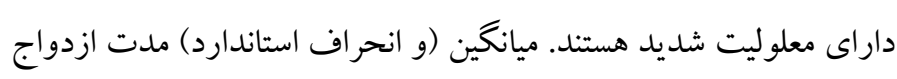

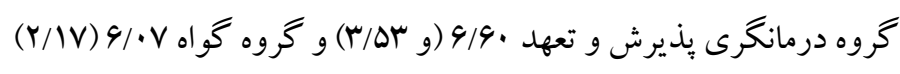

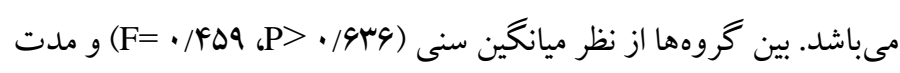

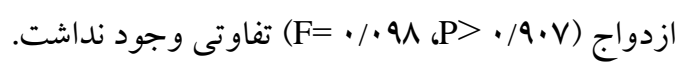

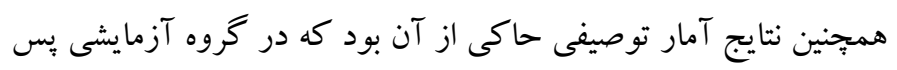

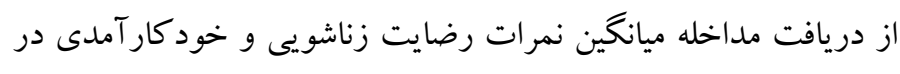
مرحله بِ آزمون و ييخيرى در مقايسه با قبل از مداخله (ييش آزمون)

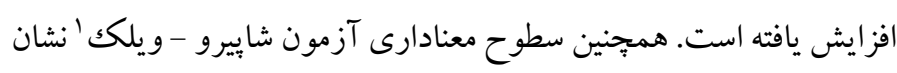

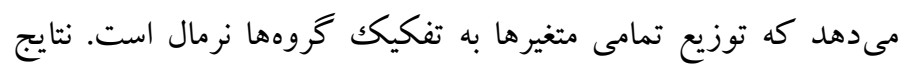

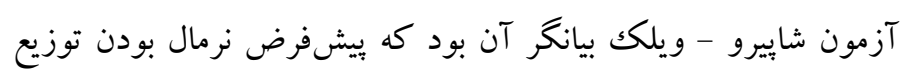

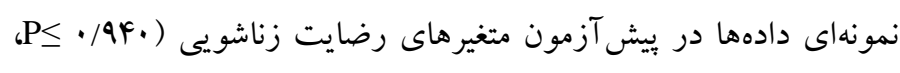

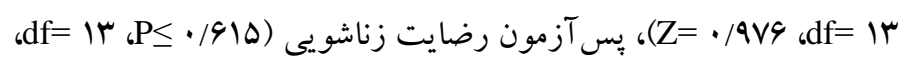

\footnotetext{
1. Shapiro-Wilk Test

2. scatter plot
}

3 . covariate 


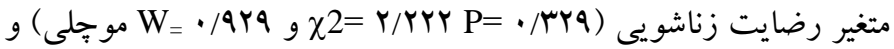

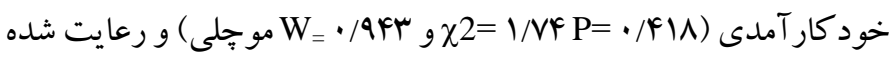
است. لذا با توجه به عدم معنادارى آزمون موجلى از آزمون كرويت مفروض براى آزمون فرضيه استفاده شد. همجنين نتايج حاصل از لامبداى ويلكز در مرحله بين آزمودنى (كروه)، درون آزمودنى (زمان) و تعامل (كروه × زمان) نشان مى ندهد كه بين كروه هاى (آزمايش و گواه) و تعامل (كروه × زمان) از لحاظ حداقل يكى از متغيرهاى وابسته (رضايت زناشويى و خود كار آمدى) تفاوت معنىدارى وجود دارد، همجينين بين زمانهاى سنجش (يس آزمون و بيخيرى) تفاوت معنى دارى وجود دارد. از آنجا كه بين گروههاى (آزمايش و كواه) و تعامل (كروه × زمان) از لحاظ حداقل يكى از متغيرهاى وابسته تفاوت وجود دارد، براى بررسى نقطه تفاوت به انجام تحليل واريانسهاى يككراهه در متن مانواى تكرارى روى هر يكك از متغيرهاى وابسته مبادرت شد كه نتايج آن در جدول ا آمده است.
FF/A • =لامبداى ويكلز) معنادار نبوده و حاكى از همخونى ضرايب ركرسيونى است. همانطور كه مشاهده مىشود آمارههاى جندمتغيرى مربوطه يعنى لامبداى ويكلز معنىدار نمىباشند (ه (ه) P. P. بنابراين مفروضه همخنى ضرايب رگرسيونى برقرار است. با توجه به برقرارى مفروضههاى تحليل واريانس آميخته با اندازه گيرى مكرر، استفاده از اين آزمون مجاز بود. بنابراين براى آزمودن فرضيه يزٔوهش از تحليل واريانس يككراهه در متن مانووا تكرارى استفاده شد. در نهايت نتايج آزمون t نشان داد كه بيش آزمون گروههاى آزمايشى و گواه در متغيرهاى وابسته (رضايت زناشويى و خود كار آمدى) معنى دار نبوده است (ه •/ P). حال به ارائه نتايج جداول استنباطى برداخته مىشود. با توجه بهاندازه اثر محاسبه شده، ·ه درصد از كل واريانسهاى گروه آزمايش و كواه ناشى از اثر متغير مستقل است. همجينين توان آمارى آزمون برابر با ا بود كه دلالت بر كفايت حجم نمونه دارد. در نهايت نتايج آزمون موجلى نشان داد كه مفروضه كرويت براى فرض برابرى واريانسهاى درون آزمودنى براى

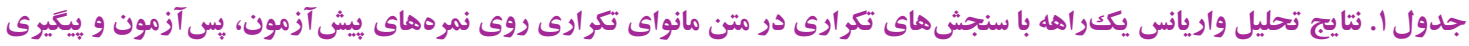

\begin{tabular}{|c|c|c|c|c|c|c|c|}
\hline Partial $\eta^{2}$ & $\mathrm{P}$ & $\mathrm{F}$ & MS & $\mathrm{DF}$ & SS & متغير وابسته & منبع تغييرات \\
\hline$\cdot / 4 A$ & $\mathrm{P} \leq \cdot / \cdot \cdot 1$ & $r \cdot / 1.9$ & $99 / 1 \% 4$ & 1 & $99 / 1+4$ & ياسخ قراردادى & \\
\hline .194 & $\mathrm{P} \leq \bullet / \cdot \cdot 1$ & rq/arl & $r q K / \cdot r \mid$ & 1 & $r q r / \cdot r \mid$ & رضايت زناشويى & \\
\hline$\cdot / \mu F$ & $P_{\leq} \bullet / \cdot r$ & $11 / 1 \wedge \Delta$ & $r / \Delta \cdot r$ & 1 & $m / \Delta \cdot r$ & موضوعات شخصيتى & \\
\hline$\cdot / r \mid$ & $\mathrm{P} \leq \cdot / \cdot \Delta$ & $\Delta / A I Y$ & $F 1 / . v 9$ & 1 & $\mathrm{FI} / \mathrm{Vq}$ & ارتباط زناشويى & \\
\hline$\cdot / M F$ & $\mathrm{P} \leq \cdot / \cdot r$ & II/YYA & $10 \cdot / \cdot 11$ & 1 & $10 \cdot / \cdot 11$ & حل تعارض & \\
\hline$\cdot / 1 \wedge$ & $P \leq \cdot / r$ & $F / M \Lambda 1$ & $10 / \cdot 10$ & 1 & $10 / \cdot 10$ & مديريت مالى & \\
\hline$\cdot /$ / A &.$/ 1$ & $N / 1 \cdot 4$ & $\Delta 9 / \Delta / \Delta$ & 1 & $\Delta 9 / \Delta / \Delta$ & اوقات فراغت & بين آزمودنى (كروه) \\
\hline.$/ \cdot \mu$ & . $/ 4 r$. &.$/ 9 \mathrm{VA}$ & $\Delta / \cdot \Delta \Lambda$ & 1 & $\Delta / \cdot \Delta \Lambda$ & روابط جنسى & \\
\hline . & $\mathrm{P} \leq \cdot / \cdot \cdot$ & Ir/אTr & NG/QYr & 1 & NG/AYr & و الدگرى & \\
\hline$\cdot / 10$ & .1 .9 & r/AYF & (Tr/ro & 1 & D & بستكان و دوستان & \\
\hline$\cdot 1 \cdot \Delta$ & $\cdot / r \cdot v$ & $1 / .91$ & Y/YIS & 1 & $r / Y 19$ & بر ابرى مرد و زن & \\
\hline$\cdot / \cdot 1$ &.$/ 91$. &.$/ \cdot 1 r$ & $\cdot / \cdot v \Delta$ & 1 & $\cdot / \cdot v \Delta$ & جهت گيرى عقيدتى & \\
\hline$\cdot / A F$ & $\mathrm{P} \leq \cdot / \cdot \cdot 1$ & $19 / 94$. & $9|r| / r \cdot F$ & 1 & $9|r| / r \cdot F$ & نمره كل & \\
\hline • & $\mathrm{P}_{\leq} \bullet \bullet \Delta$ & $9 / 91 F$ & $\mid r G Q / \wedge \Delta \Lambda$ & 1 & $\mid r q 9 / \wedge \Delta \wedge$ & خود كار آمدى & \\
\hline$\cdot / r 9$ & $\mathrm{P} \leq \cdot / \cdots 1$ & $N / A \cdot F$ & $\mid F / Q \Delta F$ & r & $r q / 9 \cdot \Lambda$ & هِاسخ قراردادى & \\
\hline$\cdot / 0$ & $\mathrm{P}_{\leq \bullet / \cdot \cdot 1}$ & $r 1 / \Delta \cdot V$ & VN/YY. & r & $109 / F F$. & رضايت زناشويى & \\
\hline$\cdot / I V$ & $\mathrm{P} \leq \cdot / \cdot \Delta$ & F/FAr & Q/DrQ & r & $19 / \cdot \Delta r$ & موضوعات شخصيتى & \\
\hline$\cdot / 19$ & $\mathrm{P} \leq \cdot / \cdot \Delta$ & r/AqF & $1 F / 994$ & r & rQ/TAV & ارتباط زناشويى & درون آزمودنى (زمان) \\
\hline$\cdot / 4 q$ & $\mathrm{P} \leq \cdot / \cdot \cdot 1$ & $1 \% / \Delta 10$ & VG/AVT & r & IOT/VFD & حل تعارض & \\
\hline.$/ \cdot 9$ & $\cdot / \mathrm{rV}$ & $r / 199$ & $F / Q 11$ & r & Q/. & مديريت مالى & \\
\hline$\cdot / r$ & $\mathrm{P} \leq \cdot / \cdot \cdot 1$ & $9 / Y V F$ & $r r / \Lambda \cdot 1$ & r & FV/G.Y & اوقات فراغت & \\
\hline
\end{tabular}




\begin{tabular}{|c|c|c|c|c|c|c|c|}
\hline.$/ .9$ & . / Iro & $r / 1.1$ & $r / \cdot V r$ & $r$ & G/1FD & روابط جنسى & \\
\hline$\cdot / 4 q$ & $\mathrm{P} \leq \cdot / \cdots 1$ & $\Lambda / v \cdot 1$ & YF/FVG & r & FN/qDH & والدگرى & \\
\hline$\cdot 119$ &.$/ \Delta$ & r/qIV & $|F / \cdot| r$ & r & $r N / r_{\Delta}$ & بستگان و دوستان & \\
\hline$\cdot / \% \mu$ & •/ & $\cdot / 9 F A$ & 1/1 1 & r & $r / r 94$ & برابرى مرد و زن & \\
\hline .1 .9$. & •/IrA & $r / \cdot V \wedge$ & 91.40 & r & $\mid r / \cdot q$. & جهت گيرى عقيدتى & \\
\hline$\cdot / A V$ & $\mathrm{P} \leq \bullet / \cdot \cdot 1$ & 1N/9V9 & r/19N/199 & r & Frag/TrV & نمره كل & \\
\hline .190 & $\mathrm{P} \leq \cdot / \cdot \cdot 1$ & $\mathrm{rq} / . \mathrm{rq}$ & YVI/TAV & r & DFY/VVF & خود كار آمدى & \\
\hline$\cdot$ / & $\mathrm{P} \leq \cdot / \cdots 1$ & $11 / T G 4$ & $19 / r \cdot r$ & r & $r N / 9 \cdot F$ & هِاسخ قراردادى & \\
\hline$\cdot / F F$ & $\mathrm{P} \leq \cdot / \cdot \cdot 1$ & $19 / V O V$ & $9 . / 9 F F$ & r & $|r| / M M q$ & رضايت زناشويى & \\
\hline$\cdot|r|$ & $\mathrm{P} \leq \cdot / \cdot 9$ & $\Delta / V V \Lambda$ & $I r / Y A$. & r & $Y Y / \Delta \Delta Q$ & موضوعات شخصيتى & \\
\hline$\cdot 1 \cdot 1$ & . / Q & $1 / 9 V r$ & $V / F F V$ & r & $\mid F / \wedge q F$ & ارتباط زناشويى & \\
\hline$\cdot / r r$ & $\mathrm{P} \leq \cdot / \cdot 9$ & $\Delta / q \cdot r$ & $M / \Delta 9 \Lambda$ & r & GV/ITV & حل تعارض & \\
\hline$\cdot / \cdot V$ &.$/ 191$ & I/VDI & r/GKr & r & V/YAF & مديريت مالى & \\
\hline$\cdot / r r$ & $\mathrm{P} \leq \bullet / \cdots \Delta$ & $\Delta / ৭ \wedge \vee$ & $10 / 499$ & r & $r \cdot / V H r$ & اوقات فراغت & تعامل: (كروه×زمان) \\
\hline . & $\mathrm{P} \leq \bullet / \cdots r$ & $9 / 4 \cdot r$ & $9 / r q Y$ & r & W/VYF & روابط جنسى & \\
\hline$\cdot / r v$ & $\mathrm{P} \leq \bullet / \cdots 1$ & $\mid r / \Delta \cdot r$ & $r \Delta / I V Y$ & r & $V \cdot / r V V$ & و الدگرى & \\
\hline$\cdot / F_{F}$ & $\mathrm{P}_{\leq \bullet \bullet}$ & G/VYI & $r F / \cdot F l$ & r & $F N / A r$ & بستگان و دوستان & \\
\hline$\cdot / r \mu$ & $P_{\leq} \bullet / \cdots F$ & $9 / 19$. & $V /$ TaF & r & IF/VAV & برابرى مرد و زن & \\
\hline •/.r & .1914 & . /FqF & $1 / 4+4$ & r & T/AVY & جهت گيرى عقيدتى & \\
\hline$\cdot / A r$ & $\mathrm{P} \leq \bullet / \cdots 1$ & $10 / 1 \wedge \mu$ & $\mid V A V / \cdot r \Lambda$ & r & $r \Delta V F / \cdot v q$ & نمره كل & \\
\hline$\cdot N r$ & $\mathrm{P} \leq \cdot / \cdot \cdot 1$ & $\Delta \Lambda / V \Delta \Lambda$ & $F \cdot N / 9 \cdot F$ & r & $\Lambda I V / r \cdot q$ & خود كار آمدى & \\
\hline
\end{tabular}

نتايج مندرج در جدول ا نشان مىدهند كه تحليل واريانس يككراهه در بر متغيرهاى (رضايت زناشويى و خود كار آمدى) معنىدار است. بنابر اين

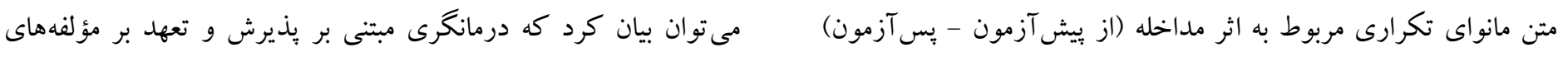

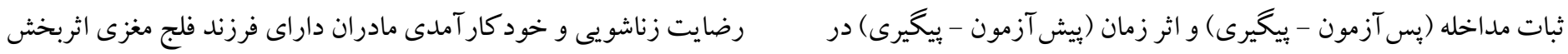

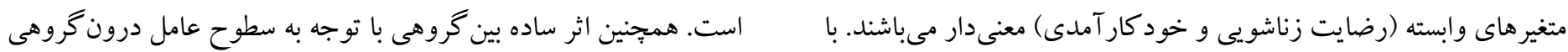

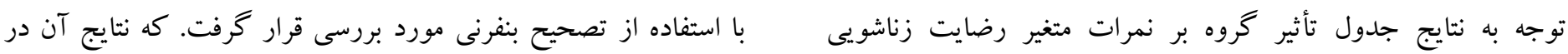
.

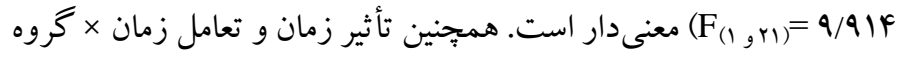

جدول ז. نتايج آزمون بنفرونى (درون كروهى و بين كروهى) براى مقايسه درمانكرى مبتنى بر يذيرش و تعهد و كروه كواه در نمرههاى ييشآزمون، يس آزمون و بيكيرى متثير هاى وابسته

\begin{tabular}{|c|c|c|c|c|c|}
\hline $\mathrm{P}$ & $\mathrm{SD}$ & تفاوت ميانگينها & \multicolumn{2}{|c|}{ موقعيت } & متغير \\
\hline $\begin{array}{l}\mathrm{P} \leq \cdot / \cdot \cdot 1 \\
\mathrm{P} \leq \cdot / \cdot \cdot 1\end{array}$ & $\begin{array}{l}r / r . . \\
F / T r V\end{array}$ & $\begin{array}{l}-19 / 9 V \\
-18 / 40\end{array}$ & 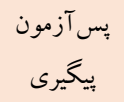 & ييش آزمون & رضايت زناشويى \\
\hline $\begin{array}{l}\mathrm{P} \leq \cdot / \cdot \cdot 1 \\
\mathrm{P} \leq \cdot / \cdot \cdot 1\end{array}$ & $\begin{array}{l}. / 911 \\
. / 919\end{array}$ & $\begin{array}{l}-9 / 9 \cdot 1 \\
r / 911\end{array}$ & 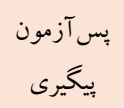 & ييش آزمون & خود كار آمدى \\
\hline $\mathrm{P} \leq \bullet / \cdots 1$ & $4 / 991$ & 19 & كواه & $\mathrm{ACT}$ & رضايت زناشويى \\
\hline $\mathrm{P} \leq \bullet \cdots \Delta$ & Y/VFA & N/9DF & كواه & $\mathrm{ACT}$ & خود كار آمدى \\
\hline
\end{tabular}


زنان شد. افرادى كه از توانشهاى عدم قضاوت، ذهن آكاهى، بذيرش و

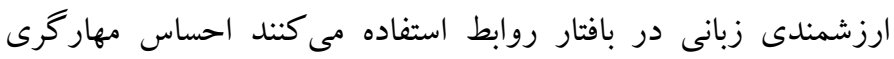

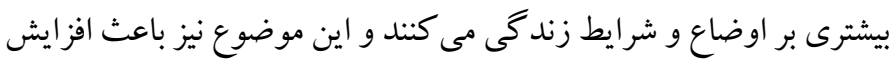

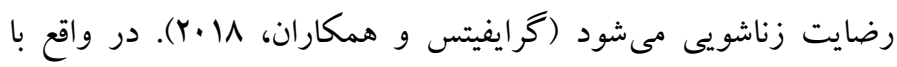

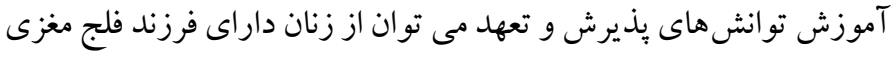

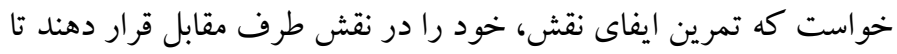

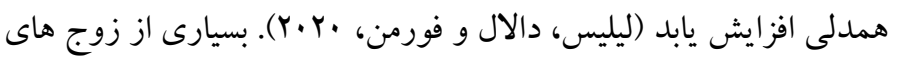

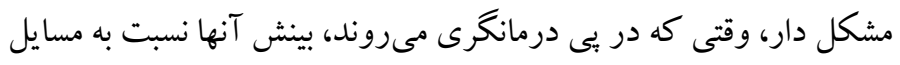

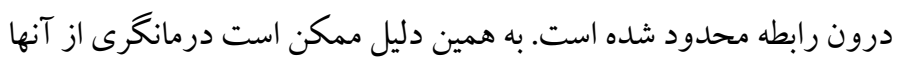
بخواهد افكار، احساسات و رفتارشان را اولين ملاقات، در قرارها و نيز

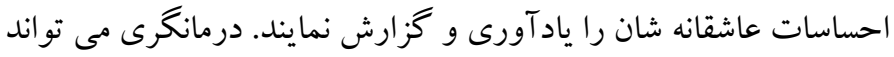
بر روى تضاد بين تجارب كذشته و حال تمركز كند. اين تضاد مى تواند نشان دهد كه اين افراد قادر بودند به روش رضايت بخشت ترى ابت ارتباط برقرار

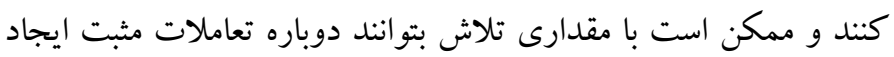
نمايند كه اين امر افزايش رضايت زناشويى را در مرحله بِ بس آزمون نشان

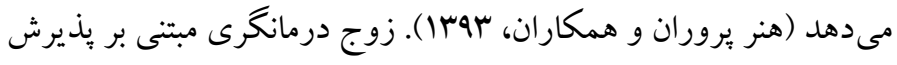

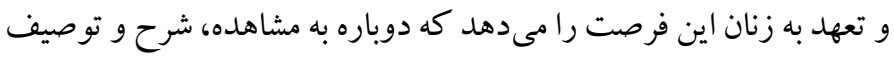
حالات هيجانى بدون يكك ديد قضاوت گرانه بيردازد و بيشتر تمركز

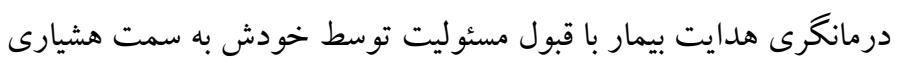

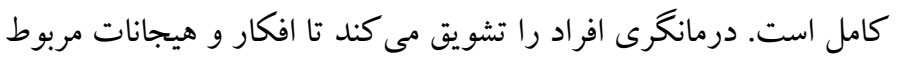
به يكك فكر، احساس، رابطه و رفتار را به صورت كامل تجربه كند بدون آنكه آنها را سر كوب كند، و در مورد آن قضاوت ارزشى كند و هيجانات ثانويه كه در خصوص وضعيت فرزند خود دارد مثل شرم، كناه، بى اعتمادى، سرزنش و تحقير را بعد از تجربه اين رفتار، فكر و احساس

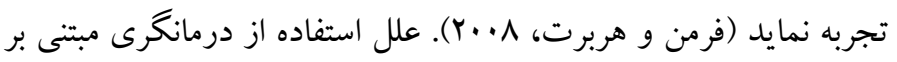
يذيرش و تعهد تمر كز بر ارزيابى و توسعهى يكك طرح درمانكرى است. در

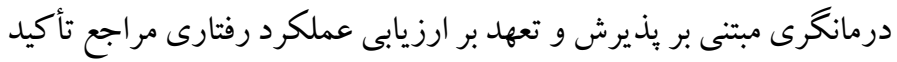

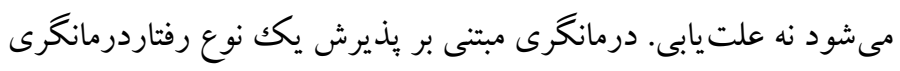

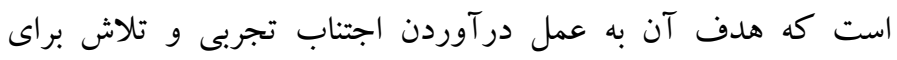
مهارگرى تجربههاى آزارنده است (هيز، استراسال و ويلسون، 1999؛

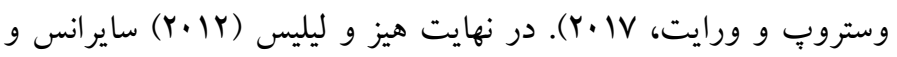

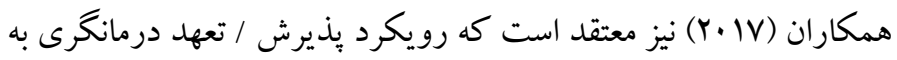

نتايج حاصل از سطح تصحيح بنفرونى نشان داد كه در پس آزمون و بيگيرى

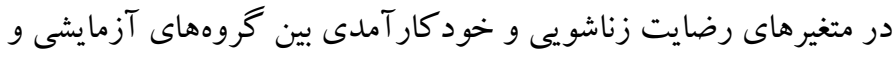

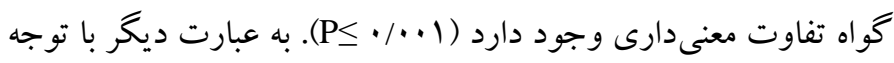

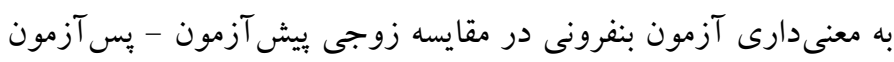

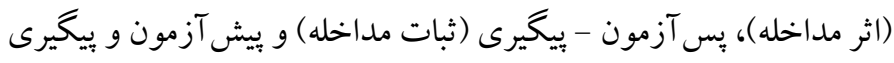

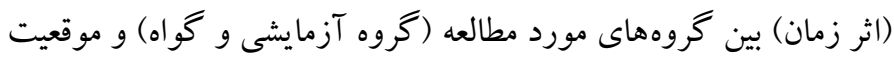

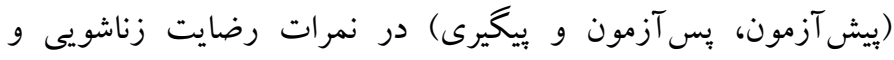

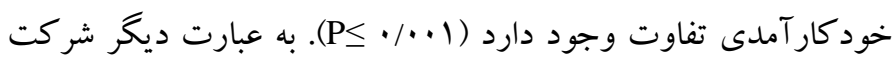

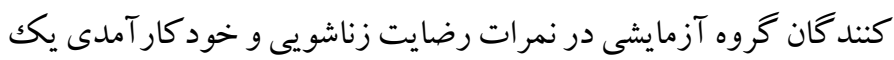
روند خطى افزايشى داشته است.

\section{بحث و نتيجه تيرى}

هدف از انجام يُزوهش حاضر هدف بِاسخكويى به اين سؤال بود كه: آيا

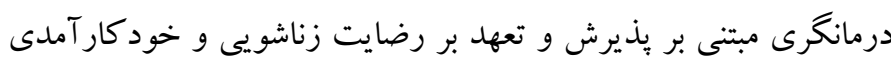

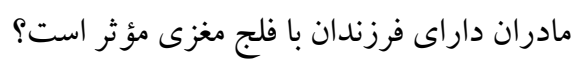

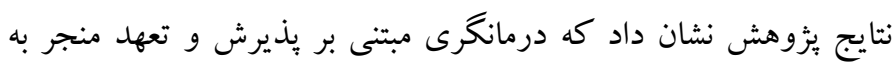

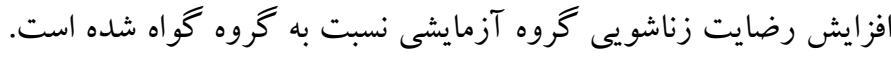

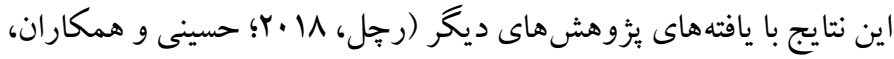

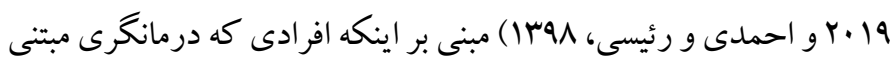
بر بذيرش و تعهل بر افزايش رضايت زناشويى اثربخش است همخوانى

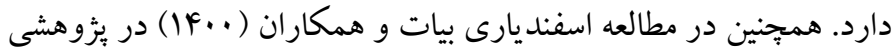
به اين نتيجه رسيدند كه علىرغم تفاوت محتوا و فرآيند دو روى آورد

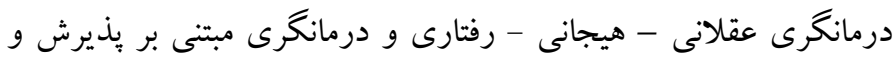

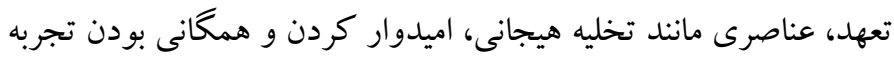

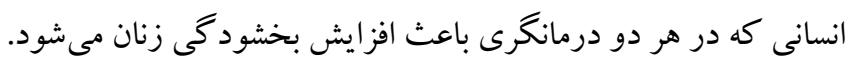

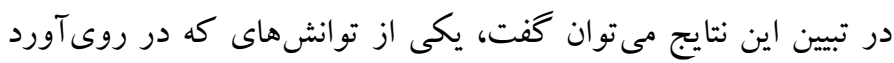

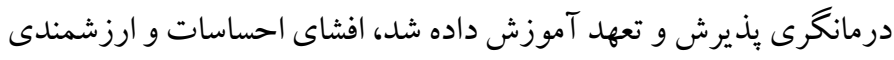

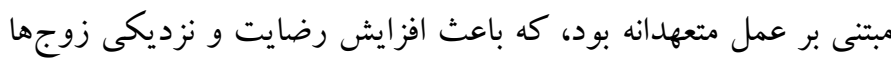

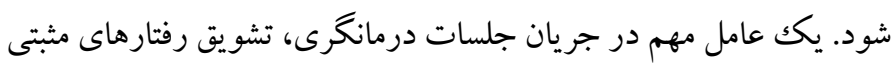

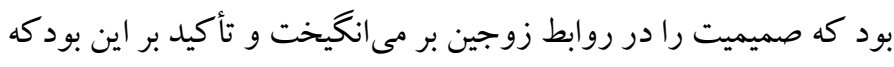

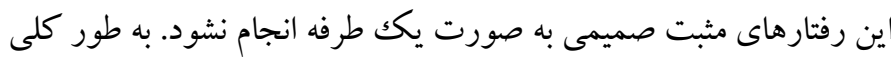
اين توانشها موجب خوب درك كردن و افزايش تفاهم و همدلى در بين 
يابد. بنابر اين تمرينات ذهن آكاهى، خود آكاهى، هشيارى بدنى و شناختى را افزايش مىدهد و اين خود آكاهى، سبب ارزيابى صحيح خود مى شود و

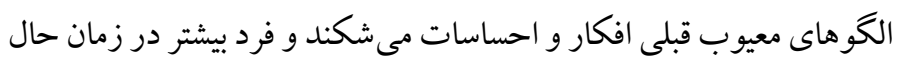

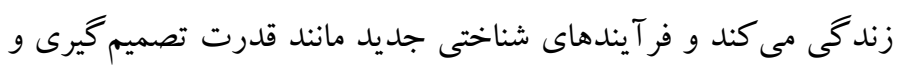
برنامهريزى تسهيل مى شود و فرد حالات مثبت ذهنى را تجربه خو اهد كرئ كرد.

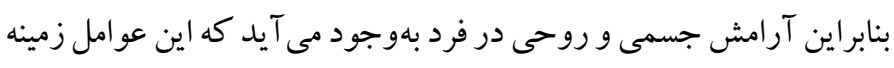

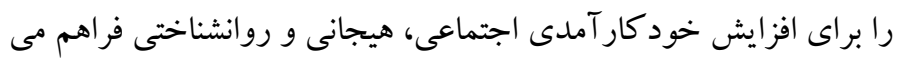

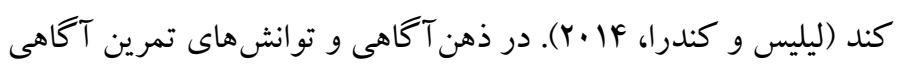

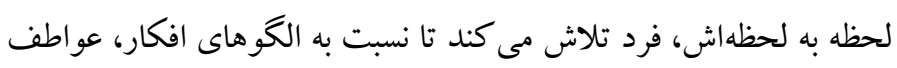

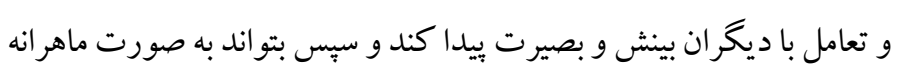

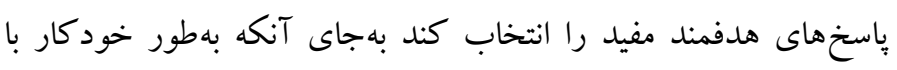

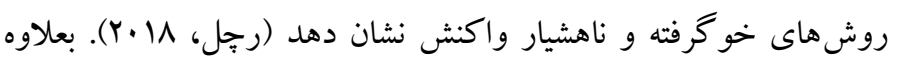

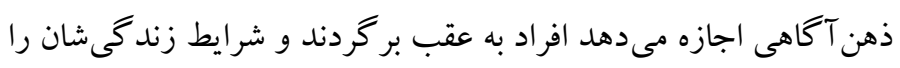

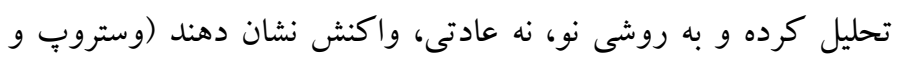

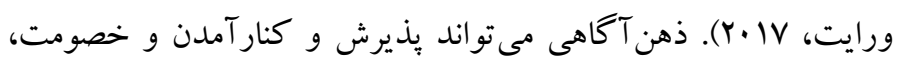

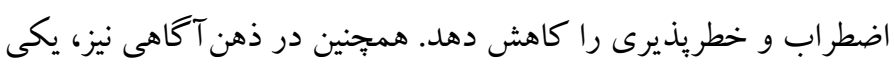

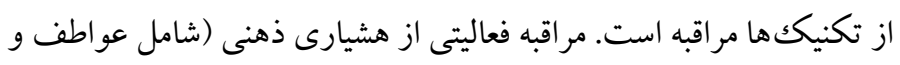

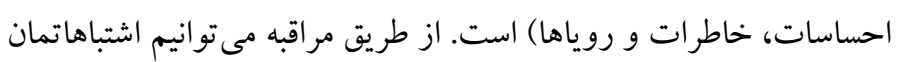

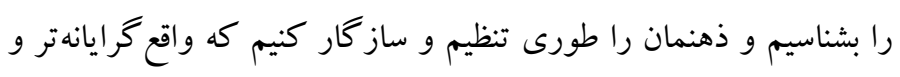

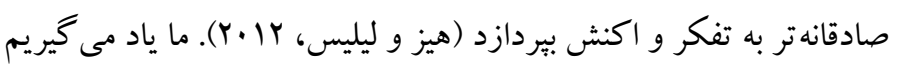

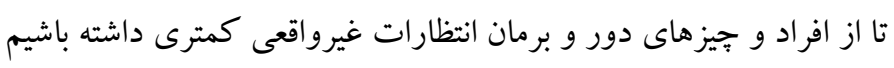

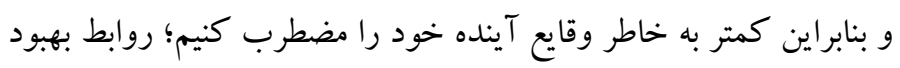

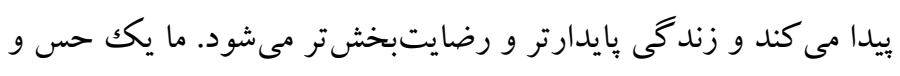

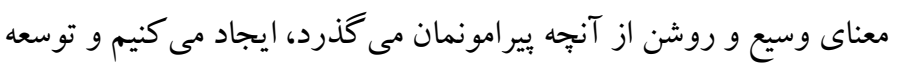

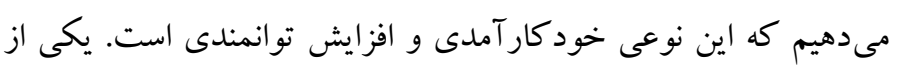
مكانيسمهاى ذهن آكاهى "آكاهى فراشناختى" است كه اشاره به باورهايى دارد كه افراد درباره تفكر خود دارند. اين دانش شامل باورهايى در مورد

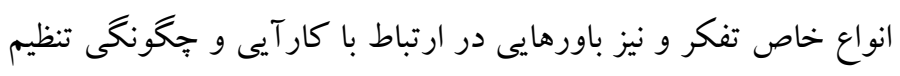

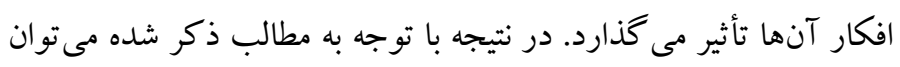

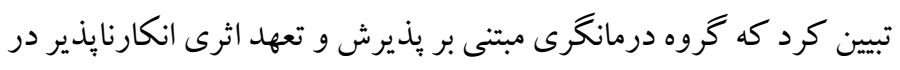

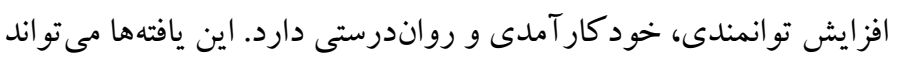

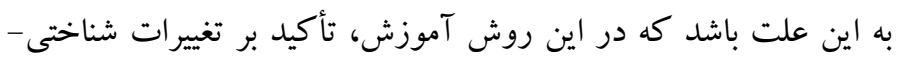

جاى آنكه روى برطرفسازى و حذف عوامل آسيبزا تمركز نمايد به

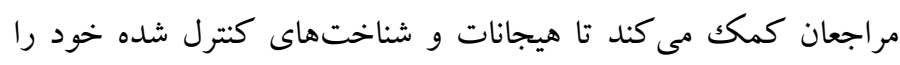
بيذيرند و خود را از كنترل قوانين كلامى كه سبب ايجاد مشكلاتشان

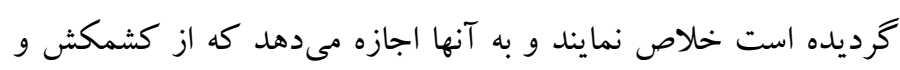
منازعه با آنها دست بردارند. بذيرش و تعهد درمانگرى اساساً فر آيند محور

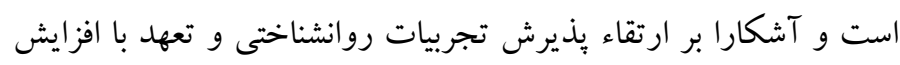

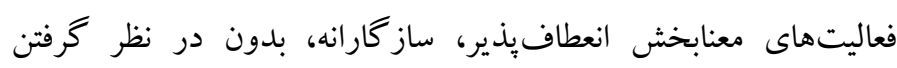

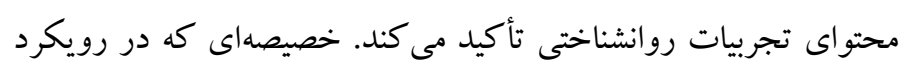

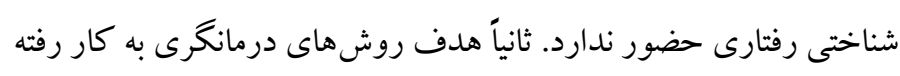

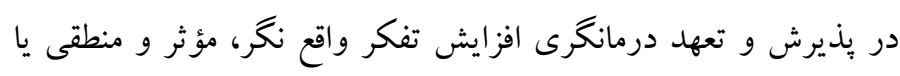

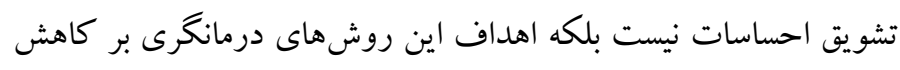

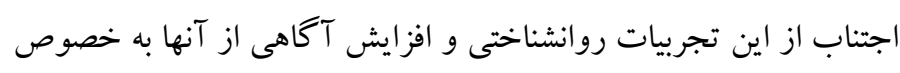

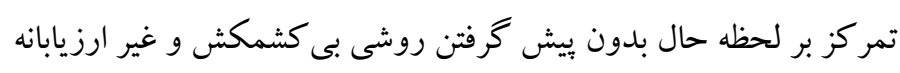

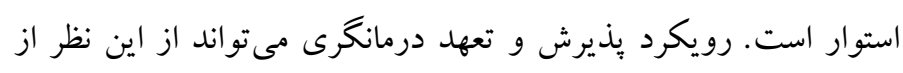

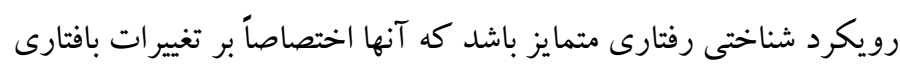

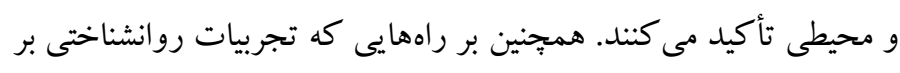

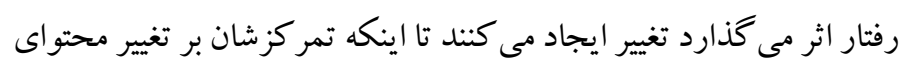
اين تجربيات باشد.

همجينين نتايج نشان داد كه درمانگرى مبتنى بر بذيرش و و تعهد منجر به

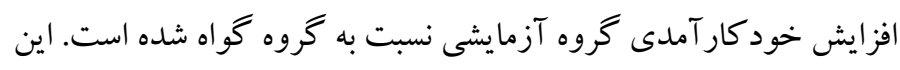

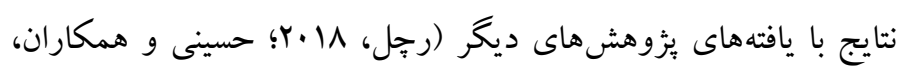

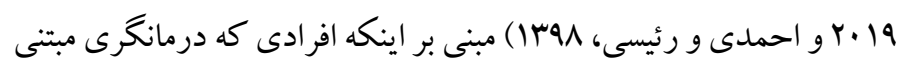

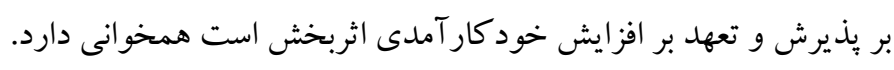

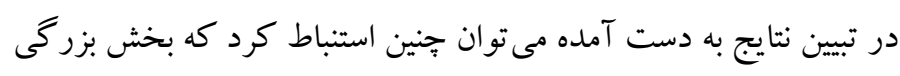

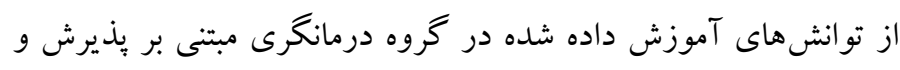
تعهد ذهن آكاهى، ارزشمند زيستن و يذيرش حالات هيجانى منفى به همان شيوهاى كه هست است كه به نوعى توجه كردن به حالات درونى فرد (مانند

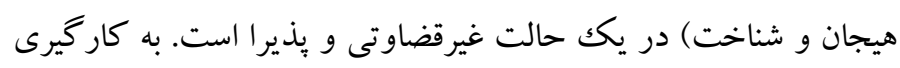

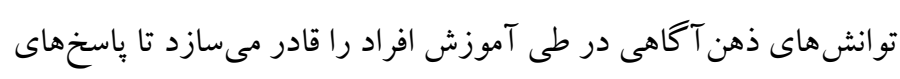

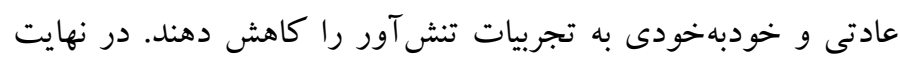
بازخورد و بصيرت شخص گسترش بيدا مى كند و فرد وقايع غيرقابل تغيير

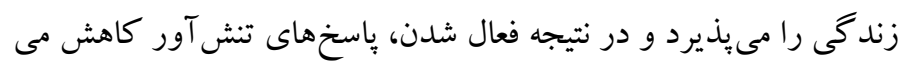


كو اه اجرا شود. همجينين، ييشنهاد مى شود از نمونه هايى با حجم بزرگتر براى دستيابى بهاندازهُ اثر واقعى برنامه استفاده شود. با توجه به نتايج يثوهش و اثربخش درمانكرى مبتنى بر بذيرش و تعهد به درمانكرانى كه در مراكز درمانگرى از جمله سازمان بهزيستى با مادران داراى فرزندان با مشكلات جسمى - حر كتى، فلج مغزى و ضايعه نخاعى سرو كار دارند، بيشنهاد مى شود از اصول و تكنيككهاى اين مداخله جهت بهبود متغيرهاى مورد بررسى و نهايتا كيفيت زندگى بهره بكيرند.

ملاحضات اخلاقى ييروى از اصول اخلاق ثئوهش: اين بثزوهش در دانشكاه علوم بزشكى كرمانشاه بررسى و با شناسه اخلاق IR.KUMS.REC.1399.776 مصوب گرديده است. مجوز اجراى يثزوهش حاضر بر كروه مطالعه شده از اداره بهزيستى شهر كرمانشاه با شماره

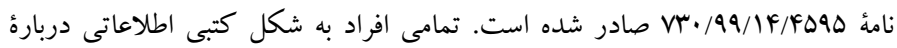
يثزوهش دريافت كرده و در صورت تمايل در بزووهش مشاركت كردند؛ اين اطمينان به

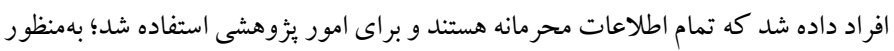
رعايت حريم خصوصى، نام و نام خانو ادگى شر كت كنند كان ثبت نشد. حامى مالى: اين يثوهش در قالب رساله دكترى و بدون حمايت مالى مىباشد. نقش هر يكك از نويسند تان: نويسنده اول محقق اصلى اين يزوهش است. نويسنده دوم استاد راهنما و نويسنده سوم استاد مشاور رساله مىباشند. تضاد منافع: نويسند كان هيج تضاد منافعى در رابطه با اين ئوهش اعلام نمى نمايند. تشكر و قدردانى: بدين وسيله از اساتيد راهنما و مشاور اين ئزوهش و نيز كاركنان بخش يثزوهش، علوم يزشكى كرمانشاه و اداره بهزيستى شهر كرمانشاه، كه در انجام اين تحقيق يارى نمودند، تشكر و قدردانى مى گردد.
رفتارى مىباشد كه خود فرد مسبب آن است. بر اين اساس به اين نكته مىتوان اشاره كرد كه كار آمدى بين فردى يكك توانش آموخته شده است نه يكك صفت كه يكك فرد داراى آن باشد يا از آن بى بهره باشد. لذا يكى برنامه جامع آموزشى كه براى تقويت باورها فردى در مورد تو انمندىهايش (خود كار آمدى) و رفتارهاى جر أتورزانه طراحى شده باشد مى تواند ديد افراد را نسبت به خودشان تغيير دهد، اعتماد به خود رادر آنها تقويت كند و روابط بينفردى آنها را بهبود بخشد و اين توانشى است كه با آموزش توانايى ارزشمند زيستن، ذهن آكاهى و يذيرش حاصل مىشود (ليليس و

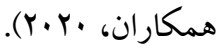
اين مطالعه داراى محدوديتهايى بود كه در ادامه به آنها اشاره مىشود. نخستين محدوديت مطالعه حاضر حجم كوجّك نمونه است. گرجه اين مطالعه دستخوش افت آزمودنىها نشد، ولى حجم كم نمونه اين مطالعه يكى از محدوديتهايى است كه مانع از بر آورد دقيق اندازه اثر برنامه شده است. محدوديت دوم مربوط به استفاده از ابزارهاى خود كزارشى است. اين ابزارها داراى مشكلات ذاتى (خطاى اندازه خيرى، عدم خويشتن نخرى و...) است. محدوديت سوم مربوط به عدم مهار كردن عوامل زمينهاى و فردى است. اين احتمال وجود دارد كه شركت كنند گان به دليل بعضى از عو امل زمينهاى اثر برنامه را بيشتر بر آورد كرده باشند. يك فرض احتمالى ديخر آن است كه افراد به دليل تمايل فردى، خوشبينى و عو املى نظاير آن اثر برنامه را بيش بر آورد كرده باشند. بيشنهاد مىشود در مطالعات آتى براى مهار كردن اثر انتظار، برنامه هاى شبه درمان (برنامه ياسيبو) بر روى گروه 


\section{References}

Ahmadi, A., \& Raeisi, Z. (2019). Effectiveness of Acceptance and Commitment Therapy in Improving Self-Efficacy of Mothers of Children with Autism. JOURNAL OF FAMILY AND RESEARCH, 16(2 (43)), 123-137. [Link]

Aminzadeh, D. M., Asmari, Y., Karimi, S., Hosiensabet, F., \& Sharifi, M. (2018). Improvement of Subjective Well-Being in Students With Physical Disability: Mental Rehabilitation Based on Teaching Emotion Regulation Skills. Practice in Clinical Psychology, 6(1), 39-46. https://doi.org/10.29252/nirp.jpcp.6.1.39. [Link]

Bagheri, P., Saadati, N., Fatollahzadeh, N., \& Darbani, SA. (2017). The Effectiveness of Group Acceptance and Commitment Therapy on Self-Efficacy and Social Adjustment of Elderly Retired. Journal of Geriatric Nursing, 3(2), 103-117. https://doi.org/10.21859/jgn.3.2.103. [Link]

Boldyreva, Uliana., Streiner, D. L., Rosenbaum, P. L., \& Ronen, G. M. (2020). Quality of life in adolescents with epilepsy, cerebral palsy, and population norms. Developmental Medicine \& Child Neurology, 62(5), 609-614. doi: 10.1111/dmcn.14450. [Link]

Cepukiene, V., Pakrosnis, R., \& Ulinskaite, G. (2018). Outcome of the solution-focused self-efficacy enhancement group intervention for adolescents in foster care setting. Children and Youth Services Review, 88(C), 81-87. doi.org/10.1016/j.childyouth.2018.03.004. [Link]

Cheng, S-T., Chen, P. P., Chow, Y. F., Chung, J W. Y., Law, A C. B., Lee, J. S. W., Tam, C. W. C. (2020). Developing a Short Multidimensional Measure of Pain Self-efficacy: The Chronic Pain Self-efficacy Scale-Short Form. The Gerontologist, 60(3), e127e136. https://doi.org/10.1093/geront/gnz041. [Link]

Edalati, A., \& Redzuan, M. (2010). Perception of women towards family values and their marital satisfaction. Journal of American Science, 6(4),132-137. doi.org/10.1177/0192513X13483292, [Link]

Ernst, G., Belrose, A., Eckhardt, J., Hild, W., Rodriguez, L. (2014). Does a participant's perceived selfEfficacy of healthcare professions improve following a Weeklong informational camp for high school students? Journal of Allied Health, 43 (3), 157-161. 6. [Link]

Esfandiyari Bayat, D. Comparison of the effectiveness of group counselling based on rational, emotional and behavioral therapy (REBT) and acceptance and commitment therapy (ACT) on forgiveness of women affected by marital infidelity. Journal of psychologicalscience, 139-148. [Link]

Fallahchai, R., Fallahi, M., and Randall, A. K. (2019) A Dyadic Approach to Understanding Associations Between Job Stress, Marital Quality, and Dyadic Coping for Dual-Career Couples in Iran. Front $\begin{array}{llll}\text { Psychology, } 10 & \text { (1), } 487 .\end{array}$ 10.3389/fpsyg.2019.00487. [Link]

Forman, E. M., Herbert, J. D. (2008). New directions in cognitive behavior therapy: acceptance based therapies, chapter to appear in w. o'donohue, je. fisher, (eds), cognitive behavior therapy: Applying empirically supported treatments in your practice, 2nd ed. Hoboken, NJ: Wiley; PP: 263-265. [Link]

Griffiths, C., Williamson, H., Zucchelli, F., Paraskeva, N., Moss, T. (2018). A systematic review of the effectiveness of acceptance and commitment therapy (ACT) for body image dissatisfaction and weight self-stigma in adults. Journal of Contemporary Psychotherapy, 48 (4), 189-204. doi: 10.1007/s10879-018-9384-0. [Link]

Hayes, S. C., Levin, M. E., Plumb-Vilardaga, J., Villatte, J. L., Pistorello, J. (2013). Acceptance and commitment therapy and contextual behavioral science: Examining the progress of a distinctive model of behavioral and cognitive therapy. Behavior Therapy, 44(2), 180-198. doi: 10.1016/j.beth.2009.08.002. [Link]

Hayes, S. C., Luoma, J. B., Bond, F. W., Masuda, A., \& Lillis, J. (2006). Acceptance and commitment therapy: Model, processes and outcomes. Behaviour Research and Therapy, 44(1), 1-25. doi: 10.1016/j.brat.2005.06.006. [Link]

Hayes, S. C., Strosahl, K. D., Wilson, K. G. (1999). Acceptance and Commitment Therapy: An Experiential Approach to Behavior Change. 3rd ed. New York, NY: Guilford. pp. 165-171. [Link]

Hayes, S. C., Strosahl, K. D., Wilson, K. G. (2012). Acceptance and commitment therapy: The process and practice of mindful change (2nd ed.). Guilford Press. [Link]

Hayes, S., Lillis S. (2012). Acceptance and commitment therapy. American psychological association publication. [Link]

Hosseini, N., Poh, Li., \& Baranovich, D, L. (2019). Enhancing Marital Satisfaction Through Acceptance and Commitment Therapy: A Review of Marital Satisfaction Improvement of Iranian Couples. International Journal of Education, Psychology and Counseling, 4 (33), 53-60. [Link] 
Jalili, N., Godarzi, M., Rassafiani, M., Haghgoo, H., Dalvand, H., \& Farzi, M. (2013). The influenced factors on quality of life of mothers of children with severe cerebral palsy: A survey study. Modern Rehabilitation, 7(3), 40-47. [Link]

Khademi, A., and Valipour, M., and Moradzadeh Khorasani, L., and Neyshabouri, S. (2015). Relationship between personality traits and marital satisfaction and its components in couples. Applied Psychology, 8 (4 (32)), 95-109. [Link]

Lee, M. H., Matthews, A. K., Park, C. (2019). Determinants of Health-related Quality of Life Among Mothers of Children With Cerebral Palsy. Journal of Pediatric Nursing, 44 (2), 1-8. doi: 10.1016/j.pedn.2018.10.001. [Link]

Lee, M. H., Matthews, A. K., Park, C. G., Vincent, C., Hsieh, K., Savage, T. A. (2020). Relationships among parenting stress, health-promoting behaviors, and health-related quality of life in Korean mothers of children with cerebral palsy. Research in Nursing \& Health, 43(6), 590-601. doi: 10.1002/nur.22074. [Link]

Lillis, J., Dallal, D.H., Forman, E.M. (2020). Innovations in Applying ACT Strategies for Obesity and Physical Activity. In Innovations in Acceptance \& Commitment Therapy: Clinical Advancements and Applications in ACT; Levin, M.E., Twohig, M.P., Krafft, J., Eds.; Context Press: Reno, NV, USA, pp. 126-139. [Link]

Lillis, J., Kendra, K. E. (2014). Acceptance and commitment therapy for weight control: Model, evidence, and future directions. The Journal of Contextual Behavioral Science, 3 (1), 1-7. doi: 10.1016/j.jcbs.2013.11.005. [Link]

Maddux, J. M. (2012). Self-Efficacy: The Power of Believing You Can. The Oxford Handbook of Positive Psychology (2nd edn). DOI: 10. 1093/oxfordhb/9780195187243.013.0031. [Link]

McCoy, S. W., Palisano, R., Avery, L., Jeffries, L., Laforme Fiss, A., Chiarello, L., Hanna, S. (2020). Physical, occupational, and speech therapy for children with cerebral palsy. Developmental Medicine \& Child Neurology, 62(1), 140-146. https://doi.org/10.1111/dmcn.14325. [Link]

McCracken, L. (2011). Mindfulness and acceptance in behavioral medicine: Current theory and practice. New Harbinger Publications. [Link]

Mehdi Imani, Seyed Ali Kazemi Rezaie, Hojatolallah Pirzadeh, Ahmad Valikhani, Seyed Vali Kazemi Rezaie, (2015). The mediating role of self-efficacy and optimism in the relation between marital satisfaction and life satisfaction among female teachers in Nahavand, Journal of Family Counseling \& Psychotherapy, 5(3), 50-71. magiran.com/p1644485. [Link]

Moradi, F., Ghadiri-Anari, A., Dehghani, A., Reza Vaziri, S., Enjezab, B. (2020). The effectiveness of counseling based on acceptance and commitment therapy on body image and self-esteem in polycystic ovary syndrome: An RCT. International Journal of Reproductive Biomedicine, 18(4), 243252. doi: 10.18502/ijrm.v13i4.6887. [Link]

NIKOUI, M., \& SAFE, S. (2005). The study of the relationship between the religion and marital satisfaction among the tehranian couples. [Link]

Påhlman, M., Gillberg, C., Wentz, E., \& Himmelmann, K. (2020). Autism spectrum disorder and attentiondeficit/hyperactivity disorder in children with cerebral palsy: results from screening in a population-based group. European Child \& Adolescent Psychiatry, 29 (11), 1569-1579. 10.1007/s00787-020-01471-1. [Link]

Parisa Bagheri, Nadereh Saadati, Noushin Fatollahzadeh, Ali Darbani, (2017). The Effectiveness of Group Acceptance and Commitment Therapy on SelfEfficacy and Social Adjustment of Elderly Retired, Journal of Geriatric Nursing, 3(2), 103. magiran.com/p1701295. [Link]

Pomaki, G., Karoly, P., \& Maes, S. (2009). Linking goal progress to subjective well-being at work: the moderating role of goal-related self-efficacy and attainability. Journal of Occupational Health Psychology, 14(2), 206-218. https://doi.org/10.1037/a0014605. [Link]

Rachael, S. (2018). Acceptance and Commitment Therapy (ACT) Informed Coaching: Examining Outcomes and Mechanisms of Change. Doctoral thesis, Goldsmiths, University of London [Thesis] http://research.gold.ac.uk/26104/. [Link]

Sairanen, E., Tolvanen, A., Karhunen, L., Kolehmainen, M., Järvelä-Reijonen, E., Lindroos, S., Peuhkuri, K., Korpela, R., Ermes, M., Mattila, E., et al. (2017). Psychological flexibility mediates change in intuitive eating regulation in acceptance and commitment therapy interventions. Public Health Nutrition, 20 (2), 1681-1691. doi: 10.1017/S1368980017000441. [Link]

Spencer, S. D., Masuda, A. (2020). Acceptance and Commitment Therapy as a Transdiagnostic Approach to Treatment of Behavioral Health Concerns: A Concurrent Multiple Baseline Design Across Participants. Clinical Case Studies. 19(3), 
163-179. doi.org/10.1177/1534650119897412. [Link]

Wang, Y., Huang, Z., Kong, F. (2020). Parenting stress and life satisfaction in mothers of children with cerebral palsy: The mediating effect of social support. Journal Health Psychology, 25(3), 416425. doi: 10.1177/1359105317739100. [Link]

Westrup, D. (2017). Wright, M.J. Learning ACT for Group Treatment: An Acceptance and Commitment Therapy Skills Training Manual for Therapists; New Harbinger Publications: Oakland, CA, USA. [Link]

Wynne, K. T. (2016). Exploring Crossover Effects Among Working Spouses Through The Lens Of Social Cognitive Theory: Soc And Work-Family Conflict (2016). Wayne State University Dissertations. Paper 1606. [Link]

Yucel, D. (2017). Work-family Balance and Marital Satisfaction: The Mediating Effects of Mental and Physical Health. Society and Mental Health, 7(3) 175-195. doi.org/10.1177/2156869317713069. [Link]

Zahra Sadat Aghaei, Hamidreza Aatami, Fariborz Dortaj, Hasan Asadzade, (2018). Comparison the effectiveness of acceptance and commitment therapy (ACT) and solution-oriented therapy on on couples' emotional regulation, Journal of Psychological Sciences, 17(68), 509514. magiran.com/p2013792. [Link] 